\title{
ARTE RUPESTRE Y CAMÉLIDOS EN EL NORTE SEMIÁRIDO DE CHILE: UNA DISCUSIÓN DESDE EL VALLE DE CHOAPA
} ROCK ART AND CAMELIDS IN THE SEMIARID NORTH OF CHILE:
A DISCUSSION FROM THE CHOAPA VALLEY

ANDRÉS TRONCOSO M. *

Los camélidos son un tipo de representación que se reitera frecuentemente en el arte rupestre del Norte Semiárido. Si bien ellos han sido tradicionalmente asociados al Período Alfarero Temprano (ca. 0-1000 DC), no se han efectuado estudios específicos sobre su composición visual con el fin de discutir tanto su homogeneidad/heterogeneidad como su filiación cronológica. El presente trabajo realiza tal labor con los camélidos del arte rupestre del valle del Choapa. Tras un análisis formal y de composición, se discute la cronología de estos motivos, proponiendo su asignación mayormente a los períodos Intermedio Tardío y Tardío (ca. 1000 a 1540 DC), evaluando tales datos con la dinámica espacial del registro arqueológico y la dinámica de la vida social prehispánica.

Palabras clave: Norte Semiárido, valle del Choapa, arte rupestre, camélidos, cronología

Camelids are one of the most ubiquitous motifs in the rock art of the prehispanic Semiarid North of Chile. Although traditionally associated with the Early Ceramics Period (O-1000 AD), no studies have examined the visual composition of these carvings to determine their homogeneity or heterogeneity, or even their chronological association. In this paper we attempt such a task by considering the camelids depicted in the Choapa River Valley. A formal and compositional analysis is employed to discuss the chronology of these designs and suggest their association with the Late Intermediate and Late Periods (1000-1540 AD). The data is evaluated in relation to the spatial dynamics of the archaeological record and to prebistoric social life dynamics.

Key words: Semiarid North, Choapa Valley, rock art, camelids, chronology

\section{INTRODUCCIÓN}

A partir del estudio de un conjunto de petroglifos provenientes del valle del Choapa ( $32^{\circ}$ Lat. S), extremo meridional del Norte Semiárido (fig. 1), este trabajo tiene como finalidad discutir y proponer una asignación cronológica para uno de los motivos más reconocidos en el arte rupestre de tal región: los camélidos.

La representación de estos animales en arte rupestre es un hecho recurrente en diferentes regiones de los Andes del Sur, como por ejemplo, el Norte Grande chileno y Noroeste Argentino, respondiendo ello a la importancia simbólica y económica que presentan estos animales dentro de la vida social de las comunidades andinas (Niemeyer et al. 1989; Aschero 1999; Berenguer 2004a, 2004b; Gallardo 2004, entre otros).

Sin embargo, mientras en el Norte Grande chileno y Noroeste Argentino, así como en otros espacios del mundo andino, se han realizado amplios esfuerzos por sistematizar estas representaciones en conjuntos estilísticos y desarrollar estrategias para identificar las especies reproducidas en los soportes rocosos (Berenguer 1998; Aschero 1999; Klanch \& Aldenderfer 2001; González 2003; Gallardo \& Yacobaccio 2005, 2007; Berenguer et al. 2007), este ejercicio no se ha efectuado en el Norte Semiárido.

\footnotetext{
* Andrés Troncoso M., Departamento de Antropología, Universidad de Chile, Av. Ignacio Carrera Pinto 1045 , $2^{\circ}$ Piso, Nuñoa, Santiago, email: atroncos@uchile.cl
} 


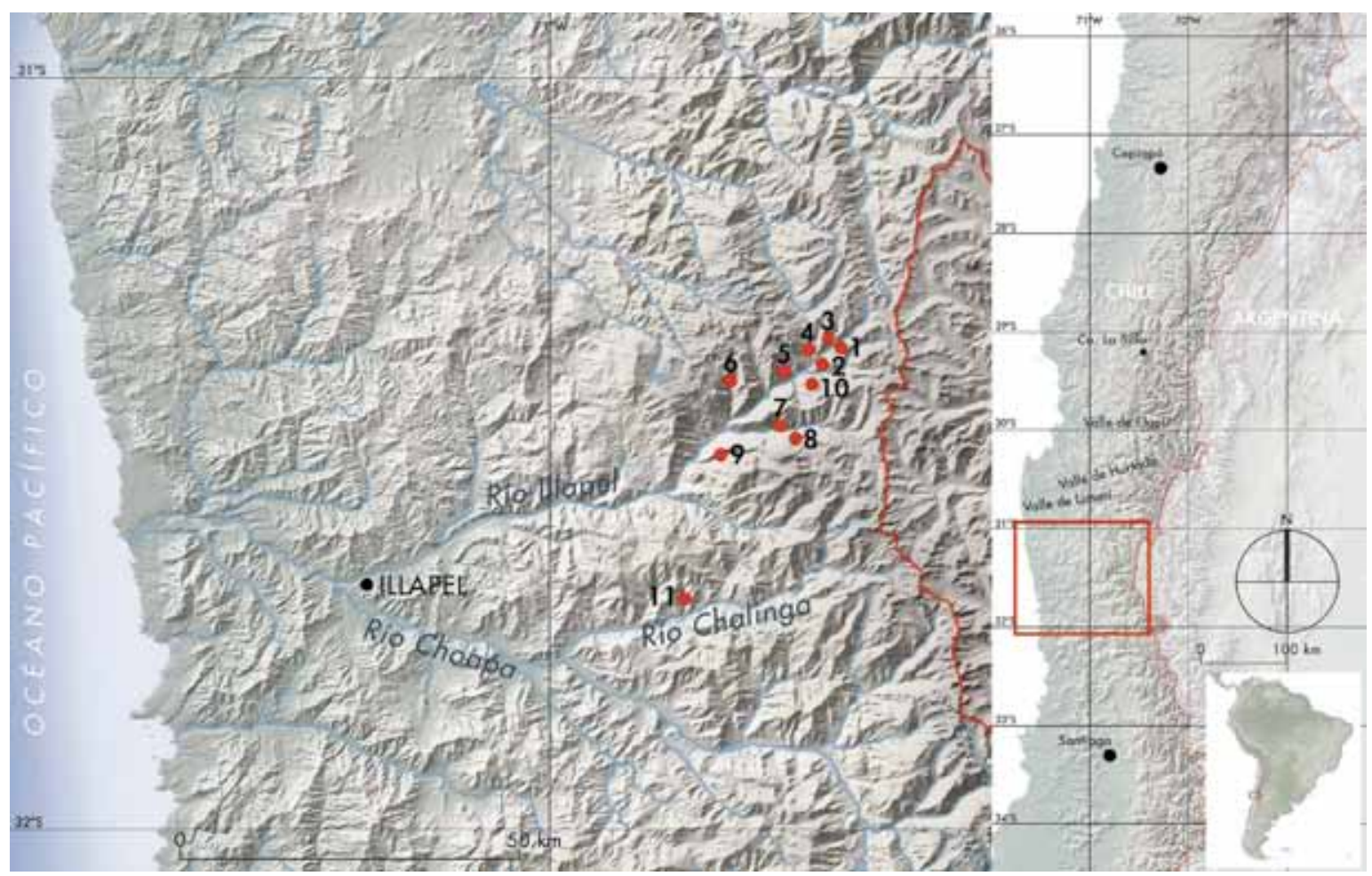

Figura 1. Mapa de la zona de estudio con indicación de las localidades mencionadas en el texto. 1) Los Mellizos, 2) La Junta, 3) La Bellaca, 4) Agua Negra, 5) Pichicavén, 6) Olla Rota, 7) Las Burras, 8) El Maitén de Las Burras, 9) Quebrada Lucumán, 10) Césped 3, 11) Ranqui 5. Figure 1. Map of the study area indicating the localities mentioned in the text. 1) Los Mellizos, 2) La Junta, 3) La Bellaca, 4) Agua Negra, 5) Pichicavén, 6) Olla Rota, 7) Las Burras, 8) El Maitén de Las Burras, 9) Quebrada Lucumán, 10) Césped 3, 11) Ranqui 5.

En efecto, en esta área no se han ejecutado investigaciones específicas orientadas a sistematizar los diferentes tipos de camélidos representados, ni se han aplicado metodologías específicas para reconocer si ellos corresponden a animales silvestres o domesticados. No obstante esta significativa falencia metodológica, se ha establecido y cimentado una prioritaria asociación entre petroglifos de camélidos y el Período Alfarero Temprano (0-900 DC) (Castillo 1985; Niemeyer et al. 1989; Niemeyer \& Ballereau 1998; Jackson et al. 2002), aunque ciertos autores han sugerido la posibilidad de que algunos camélidos sean de época posterior (p. ej., Jackson 2005), específicamente del Período Tardío (1450 a 1530 DC), pero planteando a estos más bien como excepciones antes que como un patrón.

Estas representaciones de camélidos del Norte Semiárido han sido adscritas a dos estilos de arte rupestre (Castillo 1985): Estilo La Silla, con un claro predominio de este motivo, y Estilo Limarí, con una escasa frecuencia de camélidos; ambos asociados al Período Alfarero Temprano. Si bien el segundo de ellos ha estado bajo un fuerte cuestionamiento (Troncoso 1999; Cabello 2001, 2011; Jackson et al. 2002), existiendo en la actualidad sistematizaciones alternativas
(Troncoso et al. 2008), ha sido la derivación de la cronología general de estos conjuntos estilísticos lo que ha basado la cronología de los camélidos. Esta asociación ha descansado en dos fundamentos. El primero de ellos consiste en las relaciones espaciales entre los sitios-tipos de estos estilos y los depósitos estratigráficos del Alfarero Temprano, situación por la que se asume que todos los componentes de estos estilos han de remitir a tal cronología.

El segundo se basa en que el modelo social propuesto para el Alfarero Temprano se ha fundado en comprender a estos grupos como una sociedad agropastoril (Castillo 1986; Niemeyer et al. 1989), modelo que respondió a una lógica evolucionista en la que la aparición de la alfarería traía aparejada la agricultura y, en este caso, el pastoralismo, producto de la centralidad de esta práctica en los modelos sociales del mundo andino (Núñez \& Dillehay 1995 [1979]). En esa línea, era esperable que las representaciones de camélidos y las escenas de pastoralismo fueran coherentes con tal contexto social (p. ej., Castillo 1985; Niemeyer et al. 1989).

Desafortunadamente, ambos fundamentos son hoy en día cuestionables a partir de los avances arqueológicos de las últimas décadas. Por un lado, a nivel general 
vemos que el supuesto de una relación genética entre depósitos estratigráficos y bloques de arte rupestre ha sido fuertemente criticado en el caso del Estilo Limarí a partir de una reciente revaluación del sitio Valle El Encanto (Troncoso et al. 2008) a lo que se suma el hecho de que recientes excavaciones en tal lugar han permitido recuperar alfarería asociada al Período Tardío (Troncoso 2009).

Por otro lado, a nivel específico observamos que las asignaciones cronológicas de los camélidos no han utilizado como recurso fundamental para su proposición un análisis específico de sus atributos y composiciones, por tanto, no es posible evaluar la homogeneidad/ heterogeneidad de este conjunto de motivos. En ese plano, la situación es más compleja, por cuanto si bien se han segregado en dos estilos, el criterio diferenciador a nivel de animales es la frecuencia de camélidos, sin mayores trabajos orientados a discutir la variabilidad intra e interestilos. Este hecho fue claramente indicado por Niemeyer y colaboradores (1989: 257), al comentar que "es difícil, sin embargo, conciliar el estilo La Silla con el Limarí y suponer que ambos son expresiones de la misma tradición".

Las revaluaciones sobre la prehistoria de la región en los últimos años han implicado importantes transformaciones sobre la conceptualización tanto del Período Alfarero Temprano como de los registros arqueofaunísticos. En efecto, trabajos realizados en el sector meridional del Norte Semiárido, en particular en los valles de Choapa y Combarbalá (Pavlovic 2004; Méndez et al. 2009), sugieren que las poblaciones Alfareras Tempranas responden a un modo de vida móvil con una fuerte orientación cazadora-recolectora, situación que se vislumbra al menos también para el valle de Limarí en los sitios Valle El Encanto y San Pedro Viejo de Pichasca (Troncoso \& Pavlovic 2010), sin que exista evidencia arqueológica para un modo de vida pastoril.

Los análisis de restos zooarqueológicos para contextos de este momento indican que al menos en el valle de Choapa durante el Período Alfarero Temprano no se registran camélidos domesticados, sino guanacos (Lama guanicoe) (Becker 2004). La llama (Lama glama) ingresaría a esta región recién durante el Período Tardío asociado a la incorporación de este espacio al Tawantinsuyu (Becker 2004; Troncoso 2004, Troncoso et al. 2009). Esta ausencia de llamas se reconocería también en sectores más septentrionales, pues un reciente estudio sobre los camélidos del sitio Plaza de Coquimbo ubicado en el valle de Elqui, datado hacia el año 1000 DC y uno de los pilares para proponer un pastoralismo desde el Alfarero Temprano (Castillo 1989), ha mostrado que todos los animales ahí sacrificados corresponden a guanacos, y no a llamas como se pensaba tradicionalmente (Becker \& Cartajena 2005).

Estos datos niegan a ciencia cierta el carácter ganadero del Período Alfarero Temprano desde el valle de Elqui al Sur y, por ende, debilitan el argumento central que ha permitido adscribir los camélidos a tal momento y avalar proposiciones como que "aquellas escenas de domesticación, son hasta el momento, los más firmes argumentos a favor del pastoreo y sus orígenes tempranos" (Castillo 1985: 192). Los contextos materiales de los sitios del Período Alfarero Temprano también niegan esta hipótesis, pues ellos tienen una clara orientación hacia un sistema de vida cazador-recolector, sin que se reconozcan conjuntos ergológicos asociables a un manejo inicial de camélidos y los patrones de asentamiento muestran un sistema estructurado de movilidad residencial cazadora diferente al de un sistema pastoril (Pavlovic 2004; Méndez et al. 2009).

Por tanto, hoy en día es posible cuestionar la tradicional hipótesis de una asociación entre motivos de camélidos en el arte rupestre y el Período Alfarero Temprano, pues los fundamentos que la definen no son sostenibles con los nuevos datos disponibles. Es en tal contexto que el presente trabajo tiene como objetivo discutir la asignación cronológica cultural de las representaciones de camélidos en el arte rupestre del valle del Choapa (fig. 1). Se toma como referencia básicamente el registro recuperado desde el río Illapel y su integración en el contexto regional a partir de una comparación con el registro del río Chalinga. En particular, a partir de una sistematización de las representaciones de camélidos, usando sus atributos de construcción y compositivos, se discute su filiación cronológica cultural, para posteriormente evaluar estos datos a la luz de la prehistoria local y su repercusión en el entendimiento del arte rupestre del Norte Semiárido.

\section{MATERIAL Y MÉTODO}

Con el fin de abordar la sistematización de los camélidos en el arte rupestre se trabajó en dos niveles de análisis complementarios: atributos intrínsecos y extrínsecos de los camélidos (Troncoso et al. 2009). Los primeros se refieren a una caracterización de los elementos formales que definen la construcción del camélido: cantidad de extremidades, forma del cuerpo, forma del tronco, presencia/ausencia y disposición de orejas y cola, atributos métricos (largo total, alto, largo de cuerpo y largo de extremidades) y tipos de surco. Especial atención se puso también en las angulaciones de los cuellos, definiéndose dos conjuntos de rangos de 
variabilidad, con el fin de cruzar en profundidad este atributo con los otros relevados. El primero de ellos establecía intervalos cada $20^{\circ}$ y el segundo, cada $10^{\circ}$. En este aspecto se siguieron parte de las propuestas formales de Berenguer y colaboradores (2007) y González (2003), entre otros, intentando establecer conjuntos que tuviesen la flexibilidad de abordar un gran número de ejemplares en su interior, pero que a su vez permitieran reconocer la variabilidad de la construcción visual de los camélidos. En los casos posibles se aplicó también el test propuesto por Gallardo y Yacobaccio (2005, 2007), para la identificación de especies en camélidos, el que segrega entre animales domesticados y silvestres a partir de las proporciones que se observan entre los largos de las extremidades y cuerpo.

En un segundo nivel se consideraron los atributos extrínsecos a estas representaciones, es decir, las asociaciones a las que están sujetas, las que incluyeron, por un lado, la existencia de asociación con otros animales y/o antropomorfos y, por otro, la explicitación de escenas de pastoreo o interacción con humanos.

Posteriormente, esta información fue cruzada con la distribución regional de los diseños y la información disponible sobre las ocupaciones humanas identificadas en tales espacios, con el fin de discutir los conjuntos construidos en una primera instancia dentro del panorama regional. De esta manera se planteó un análisis que estableciera en un inicio un análisis formal de los camélidos, para luego - a partir de sus atributos morfológicos, escénicos y contextuales- discutir su filiación cronológico-cultural y relación con la prehistoria local.

El análisis formal, escénico y contextual se aplicó sobre un total de 221 motivos de camélidos provenientes de un total de 97 bloques de arte rupestre ubicados a lo largo del río Illapel, específicamente de la cuenca superior (Tablas 1 y 2), los que representan un 43,7\% del total de soportes con camélidos presentes en el Illapel y un 36,1\% de los bloques con camélidos trabajados en el Choapa (Tabla 2). Se ocupó esta muestra pues los motivos provienen de los sitios registrados más exhaustivamente en terreno ${ }^{1}$ y eran los que presentaban un mayor grado de completitud, debido al recurrente deplacamiento que ocurre en los bloques de arte rupestre de la zona.

El análisis de atributos métricos se realizó únicamente sobre un total de 154 casos (69,7\% del total trabajado), que se corresponden con los que presentaban excelentes condiciones de preservación para realizar de manera idónea todas las mediciones.

\section{RESULTADOS}

Para ordenar y agrupar los camélidos se procedió en primera instancia a dividirlos en dos grandes grupos a partir de su forma de representación en función de los atributos intrínsecos considerados. Uno de ellos, el más

Tabla 1. Proveniencia de la muestra de camélidos analizados. Table 1. Origin of the camelid samples analyzed.

\begin{tabular}{|c|c|c|c|}
\hline Sector & Sitio & Número de bloques & Número camélidos \\
\hline Agua Negra & Agua Negra 1 & 1 & 5 \\
\hline La Bellaca & Bellaca 1 & 3 & 11 \\
\hline La Bellaca & Bellaca 4 & 1 & 15 \\
\hline El Maitén de Las Burras & El Maiten 5 & 13 & 22 \\
\hline La Junta & La Junta 1 & 5 & 8 \\
\hline La Junta & Tres Quebradas & 1 & 1 \\
\hline Las Burras & Las Burras 10 & 4 & 5 \\
\hline Las Burras & Las Burras 6 & 3 & 4 \\
\hline Los Mellizos & Los Mellizos & 31 & 76 \\
\hline Los Mellizos & Mellizos 2 & 2 & 6 \\
\hline Los Mellizos & Meseta 1 & 5 & 19 \\
\hline Olla Rota & Olla Rota 1 & 2 & 2 \\
\hline Pichicavén & Pichicavén 1 & 22 & 43 \\
\hline \multirow[t]{2}{*}{ Quebrada Lucumán } & Quebrada Lucumán & 4 & 4 \\
\hline & Total & 97 & 221 \\
\hline
\end{tabular}


Tabla 2. Distribución y frecuencias de camélidos en el arte rupestre del valle de Choapa. Table 2. Distribution and frequency of camelids in Choapa Valley rock art.

\begin{tabular}{|c|c|c|c|c|}
\hline Valle & Sector & $\begin{array}{c}\text { Bloques de arte } \\
\text { rupestre }\end{array}$ & $\begin{array}{c}\text { Bloques con } \\
\text { camélidos }\end{array}$ & $\begin{array}{c}\text { Porcentaje bloque } \\
\text { con camélidos }\end{array}$ \\
\hline Illapel & Curso superior & 817 & 207 & $25,3 \%$ \\
\hline & Curso medio & 230 & 13 & $5,6 \%$ \\
\hline & Curso inferior & 16 & 2 & $12,5 \%$ \\
\hline Total Illapel & & 1063 & 222 & $20,8 \%$ \\
\hline Chalinga & Curso superior & 205 & 10 & $10,8 \%$ \\
\hline & Curso medio & 333 & 36 & $3,8 \%$ \\
\hline Total Chalinga & Curso inferior & 29 & 1 & $8,2 \%$ \\
\hline Total general & & 567 & 47 & $16,5 \%$ \\
\hline
\end{tabular}

frecuente (217 de 221), correspondió a camélidos con un bajo grado de figuración y que se definían por su construcción básicamente a partir de líneas rectas o rígidas. El segundo, muy escaso y presente en un solo sitio (cuatro de 221), correspondió a camélidos con un grado alto de figuración y cuya producción visual descansaba en el uso de líneas curvas que generan representaciones con volumen y de carácter más naturalista.

Sobre esta clasificación, el paso siguiente requería establecer una sistematización y tipología dentro de cada conjunto. Para el segundo grupo esta acción no era mayormente necesaria, pues consistía en cuatro ejemplares, todos muy homogéneos, por lo que fueron abordados a partir de la metodología de trabajo propuesta por Gallardo y Yacobaccio (2005, 2007). En contraposición, para el primer conjunto se intentó establecer agrupaciones a partir de las relaciones entre alto y largo de los camélidos, ejercicio que no mostró utilidad para crear segregaciones debido a la concentración de los valores (Gráfico 1). Por el contrario, este aspecto indica una cercanía del conjunto analizado sugiriendo un importante grado de homogeneidad en sus atributos métricos. Esta tendencia a lo homogéneo es coherente con el bajo registro de superposiciones para los camélidos $(\mathrm{N}=16)$, y donde recurrentemente $(\mathrm{N}=14)$ ellas se disponen sobre otros motivos, patrón que es también coherente con el hecho que no hay mayores diferencias de pátinas entre los camélidos que comparten espacio dentro de un mismo bloque rocoso.

Por lo anterior, se decidió establecer una sistematización a partir de diferentes proporciones ( $\mathrm{p}$. ej., patas delanteras y tronco, patas traseras y tronco, patas delanteras/tronco y patas traseras/tronco), la que nuevamente mostró una homogeneidad del conjunto,

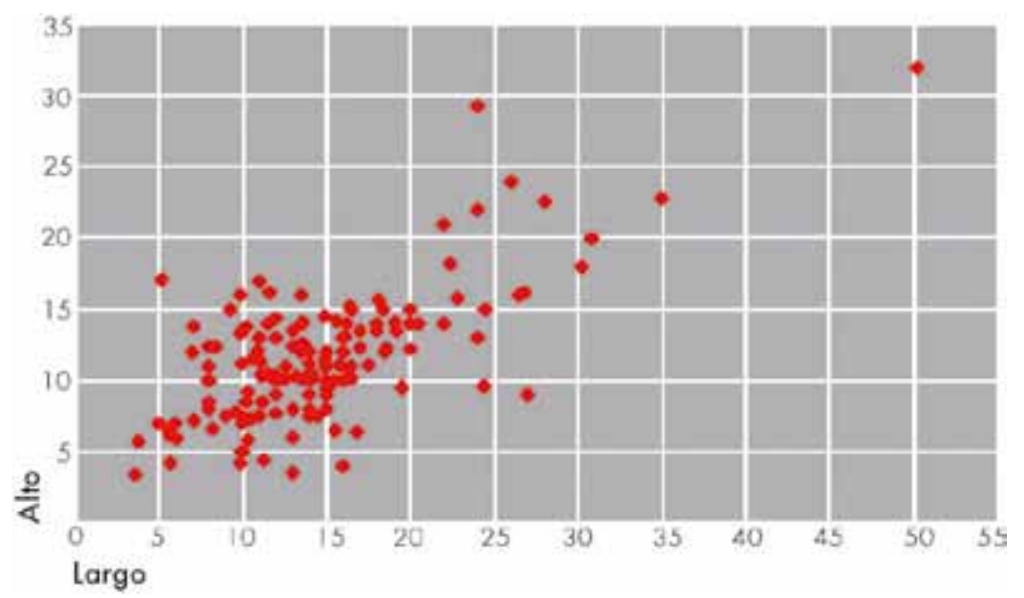

Gráfico 1. Distribución de atributos métricos de camélidos estudiados (largo-alto) sobre 154 casos. Medidas en centímetros. Graph 1. Distribution of metric attributes among the camelids studied (length-height), based on 154 cases. Measured in centimeters. 
la que se replicó al aplicar cluster analysis en el programa SPSS, sin conseguir resultados que permitiesen establecer una agrupación clara de los motivos a partir de sus atributos intrínsecos.

Tabla 3. Clasificación y representación de categorías de camélidos reconocidas en el estudio.

Table 3. Classification and categorical representation of camelids identified in the study.

\begin{tabular}{|c|c|c|c|}
\hline Conjunto & Subconjunto & Total & $\%$ \\
\hline $\begin{array}{c}\text { Camélidos } \\
\text { lineales }\end{array}$ & IA: 2 patas & 16 & $7,2 \%$ \\
\hline & IB: 3 patas & 21 & $9,5 \%$ \\
\hline & IC: 4 patas & 172 & $77,8 \%$ \\
\hline & ID: 5 patas & 6 & $2,7 \%$ \\
\hline & IE: 6 patas & 1 & $0,5 \%$ \\
\hline Camélidos & Total conjunto & 217 & $98,2 \%$ \\
\hline no lineales & Total conjunto & 4 & $1,8 \%$ \\
\hline & Total general & 221 & $100 \%$ \\
\hline
\end{tabular}

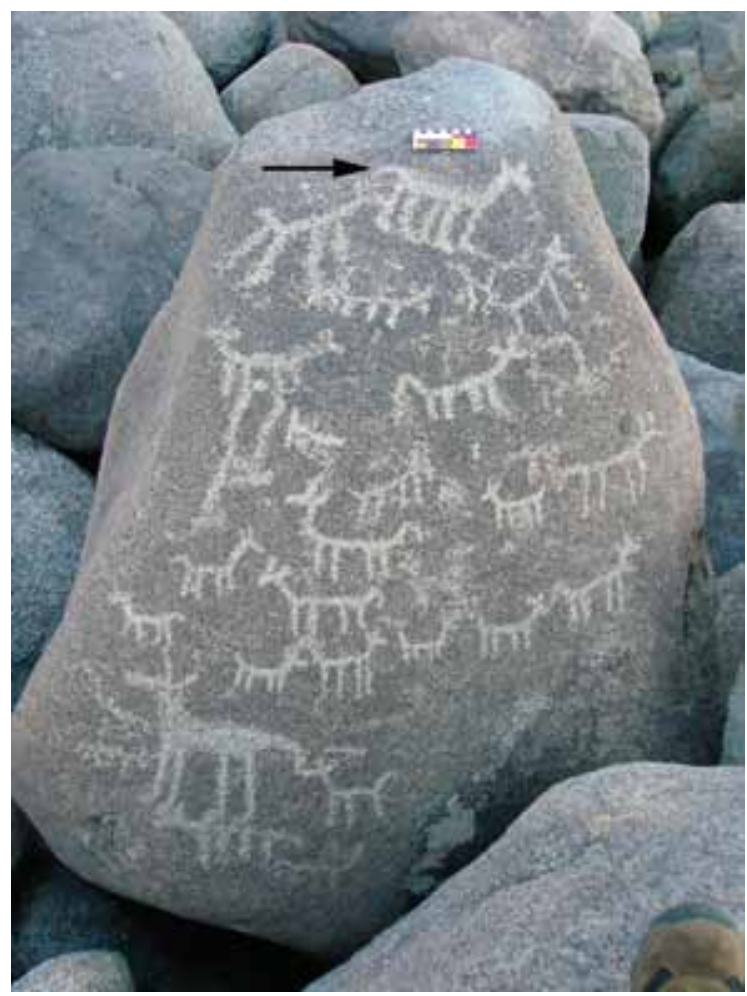

Figura 2. Conjunto de camélidos lineales del valle del Choapa, sector La Bellaca. Se indica camélido con cinco extremidades.

Figure 2. Group of line-drawn camelids in La Bellaca sector, Choapa Valley. Arrow indicates camelid with five extremities.
Ante estos resultados, se optó por usar a manera de elemento principal para su clasificación el número de extremidades que presentaban los camélidos. Debido a que su variabilidad no era tan alta, abarcando desde ejemplares con dos y hasta siete patas, fue posible agrupar conjuntos significativos, permitiendo evaluar su variabilidad interna (Tabla 3). En apoyo a este componente, se usaron las angulaciones de los cuellos en relación con los cuerpos, los que si bien se dispersan ampliamente, se consideró importante pues presentaban algunas concentraciones significativas y ha sido un criterio utilizado en la literatura arqueológica para discutir la cronología de algunas representaciones de camélidos en otras áreas (Gallardo \& Vilches 1995, 2001; Vilches \& Uribe 1999; Sepúlveda 2004, 2008). Por medio de estos criterios, especialmente el primero, se segregaron siete conjuntos de camélidos, los que serán discutidos en su particularidad a continuación.

\section{Conjunto I: Camélidos lineales}

Como indicamos, este conjunto se encuentra compuesto por un total de 217 ejemplares, los que han sido divididos en seis subconjuntos a partir de la cantidad de extremidades que ellos presentan (Tabla 3) (fig. 2).

Subconjunto IA: Camélidos de dos extremidades

Este subconjunto cuenta con un total de 16 ejemplares bastante homogéneos y con poca variabilidad, la que se refiere más que nada a la presencia/ausencia de segmentos del cuerpo (fig. 3). Se tiende a representar recurrentemente las cabezas, las colas y las orejas (Tabla 4), con un 50\% de casos en que coexisten todos estos elementos. En relación con las posiciones de colas y orejas, predominan los especímenes con orejas hacia arriba y colas horizontales (Tabla 4).

Las angulaciones que presentan los cuellos se concentran en el intervalo entre los $81^{\circ}$ y $100^{\circ}(\mathrm{N}=13$ casos, $81,3 \%$ ), y más específicamente entre los $85^{\circ}$ y $94^{\circ}$ ( $\mathrm{N}=12,75 \%$ ) (Tabla 5 ). No se observa una tendencia de asociación entre ángulos de cuello y los atributos de orejas y colas.

En términos técnicos, hay un predominio de la creación de surcos lineales continuos y, de la misma manera, métricamente no hay una gran variabilidad (Tabla 4). Aunque se encuentran desviaciones estándar altas, ellas se deben a un solo caso que se dispara en sus atributos métricos.

Al analizar la conformación escénica de estos camélidos, nos encontramos con que en tres casos (20\%) se encuentran en una composición interpretable como 
Tabla 4. Atributos generales de cada subconjunto de camélidos definido (DS = Desviación estándar). Table 4. General attributes of each camelid subset (DS = Standard deviation).

\begin{tabular}{|c|c|c|c|c|c|c|c|c|c|c|c|}
\hline 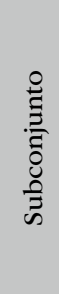 & : & 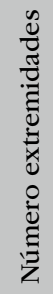 & 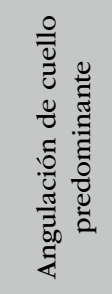 & 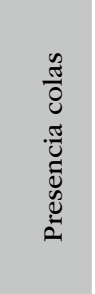 & 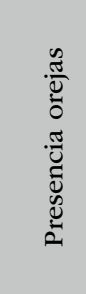 & 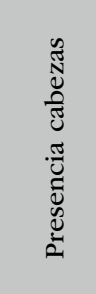 & 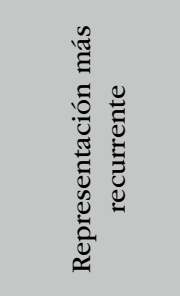 & 苋 & 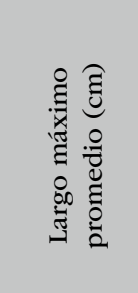 & 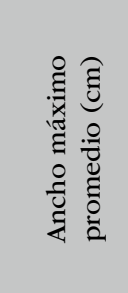 & 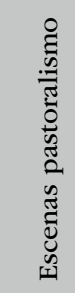 \\
\hline IA & 16 & 2 & $\begin{array}{c}81^{\circ} \mathrm{a} \\
100^{\circ} \\
(81,2 \%)\end{array}$ & $73,3 \%$ & $73,3 \%$ & $87,5 \%$ & $\begin{array}{c}\text { Orejas hacia } \\
\text { arriba y colas } \\
\text { horizontales } \\
\quad(54,5 \%)\end{array}$ & $\begin{array}{c}\text { Lineal continuo: } \\
62,5 \% \\
\text { Lineal } \\
\text { discontinuo: } \\
37,5 \%\end{array}$ & $\begin{array}{c}8,7 \\
\text { (DS: 6) }\end{array}$ & $\begin{array}{c}9,8 \\
\text { (DS: } 6,4)\end{array}$ & $20 \%$ \\
\hline IB & 21 & 3 & $\begin{array}{c}81^{\circ} \mathrm{a} \\
100^{\circ} \\
(47,6 \%)\end{array}$ & $95,2 \%$ & $76,2 \%$ & $90,5 \%$ & $\begin{array}{c}\text { Colas y orejas } \\
\text { hacia arriba } \\
(55 \%)\end{array}$ & $\begin{array}{c}\text { Lineal continuo: } \\
57,1 \% \\
\text { Lineal } \\
\text { discontinuo: } \\
38,1 \% \\
\text { Lineal } \\
\text { continuo/areal: } \\
4,8 \%\end{array}$ & $\begin{array}{c}14,9 \\
(\mathrm{DS}: 4,2)\end{array}$ & $\begin{array}{c}12,5 \\
\text { (DS: } 2,7)\end{array}$ & $9,1 \%$ \\
\hline IC & 172 & 4 & $\begin{array}{c}81^{\circ} \mathrm{a} \\
100^{\circ} \\
(31,4 \%) \\
\text { y } 101^{\circ} \\
\text { a } 120^{\circ} \\
(31,4 \%)\end{array}$ & $90,1 \%$ & $75 \%$ & $91,8 \%$ & $\begin{array}{c}\text { Colas y orejas } \\
\text { hacia arriba } \\
(30,3 \%)\end{array}$ & $\begin{array}{c}\text { Lineal continuo: } \\
68,6 \% \\
\text { Lineal } \\
\text { discontinuo: } \\
28,5 \% \\
\text { Lineal } \\
\text { continuo/areal: } \\
2,9 \%\end{array}$ & $\begin{array}{c}13,6 \\
(\mathrm{DS}: 4,1)\end{array}$ & $\begin{array}{c}10,5 \\
\text { (DS: } 3,1)\end{array}$ & $8,2 \%$ \\
\hline ID & 6 & 5 & $\begin{array}{l}101^{\circ} \mathrm{a} \\
120^{\circ} \\
(50 \%)\end{array}$ & $100 \%$ & $100 \%$ & $100 \%$ & $\begin{array}{c}\text { Colas hacia } \\
\text { abajo y orejas } \\
\text { hacia arriba } \\
(66,7 \%)\end{array}$ & $\begin{array}{c}\text { Lineal continuo: } \\
71,4 \% \\
\text { Lineal } \\
\text { discontinuo: } \\
14,3 \% \\
\text { Lineal } \\
\text { continuo/areal: } \\
14,3 \%\end{array}$ & $\begin{array}{c}17,9 \\
\text { (DS: } 11,4)\end{array}$ & $\begin{array}{c}13,2 \\
\text { (DS: } 6,6)\end{array}$ & 0 \\
\hline I E & 1 & 6 & $\begin{array}{c}81^{\circ} \mathrm{a} \\
100^{\circ} \\
(100 \%)\end{array}$ & $0 \%$ & $100 \%$ & $100 \%$ & $\begin{array}{l}\text { Oreja hacia } \\
\text { atrás y sin } \\
\text { cola }(100 \%)\end{array}$ & $\begin{array}{l}\text { Lineal continuo: } \\
100 \%\end{array}$ & 15,8 & 11,1 & 0 \\
\hline I F & 1 & 7 & $\begin{array}{c}81^{\circ} \mathrm{a} \\
100^{\circ} \\
(100 \%)\end{array}$ & $100 \%$ & $100 \%$ & $100 \%$ & $\begin{array}{c}\text { Oreja hacia } \\
\text { atrás y cola } \\
\text { hacia abajo } \\
(100 \%)\end{array}$ & $\begin{array}{l}\text { Lineal continuo: } \\
100 \%\end{array}$ & 24,4 & 9,6 & $100 \%$ \\
\hline
\end{tabular}

escena de pastoralismo, básicamente por la presencia de antropomorfos y lazos que unen a ambos seres (fig. 3d). Por sobre ello, todos los casos comparten panel ya sea con antropomorfos u otros camélidos. En este contexto, los camélidos en escenas de pastoreo presentan angulaciones de cuello tanto de $90^{\circ}(\mathrm{N}=2)$, como de $120^{\circ}(\mathrm{N}=1)$, sin que se observe un patrón con relación a cabezas y colas, ni con las técnicas de producción. Dentro de este grupo se integra el ejemplar con los atributos métricos más altos de los camélidos.

En resumen, encontramos en este subconjunto una realidad bastante homogénea, con una conformación que prioriza las representaciones de colas, cabezas y cuellos, así como una técnica de producción de surcos basado en el uso del trazo lineal continuo. Tienden a representarse en asociación a otros camélidos y/o 

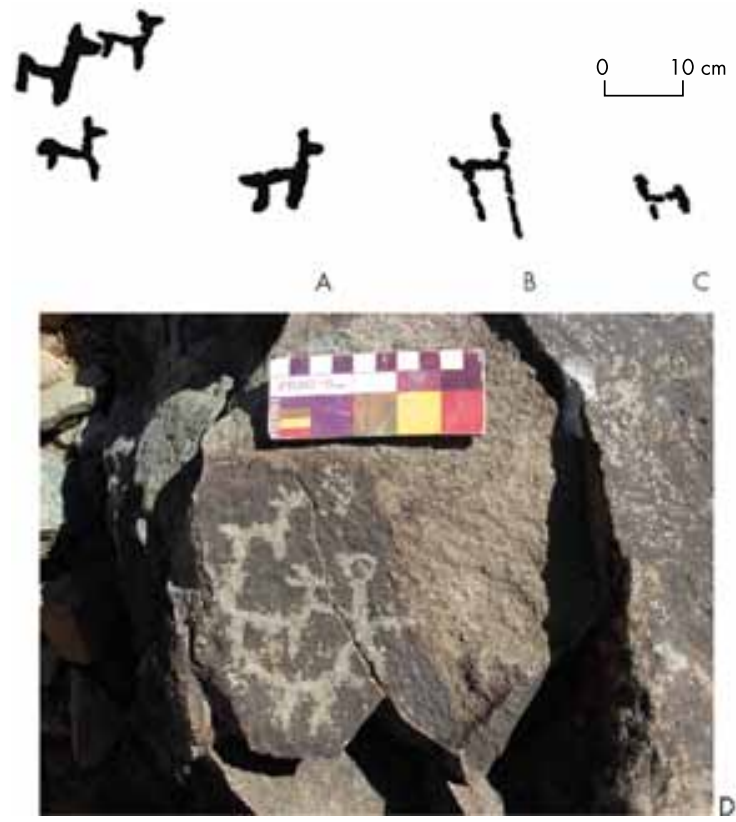

Figura 3. Camélidos lineales con dos extremidades: a) Agua Negra, b) Los Mellizos, c) Pichicavén y d) Las Burras.

Figure 3. Line-drawn camelids with two extremities: a) Agua Negra, b) Los Mellizos, c) Pichicavén and d) Las Burras.

personajes humanos, con presencia de escenas de pastoralismo en su interior. Así también, estos camélidos presentan diferentes grados de esquematismo, dado básicamente por la rigidez del torso y angulaciones con sus patas y cuello, lo que produce ciertos matices al interior del conjunto, pero sin llegar a desvirtuar su homogeneidad. La variabilidad se da a nivel de los atributos métricos, con un ejemplar que se dispara en sus medidas, pero que podemos interpretar como un outlier que no aporta mayor variabilidad al conjunto. De hecho está presente en un panel que se caracteriza por diseños de gran tamaño, en particular el personaje antropomorfo que lo acompaña, por lo que este factor puede estar influenciando tal atributo.

Subconjunto IB: Camélidos de tres extremidades

Comprende un total de 21 ejemplares ( $9,5 \%)$, bastante homogéneos entre sí (fig. 4), con una alta representación de cabezas, colas y orejas (Tabla 4), los que están presentes en casi todos los ejemplares ( $\mathrm{N}=15,71,4 \%)$. En su disposición predominan los camélidos con orejas y colas hacia arriba (Tabla 4).

Las angulaciones de cuello de este subconjunto son algo más variadas que las del anterior, aunque vuelve a existir una concentración en el intervalo entre los $81^{\circ}$ y $100^{\circ}(\mathrm{N}=10,47,6 \%)$, y más específicamente entre los $85^{\circ}$ y $94^{\circ}(\mathrm{N}=8 ; 38,1 \%)$ (Tabla 5). Nuevamente las distribuciones de colas y orejas se dan en los diferentes ángulos de cuellos, resaltando que los ejemplares sin orejas se concentran en la angulación $85^{\circ}-94^{\circ}$.

Tabla 5. Distribución de angulaciones de cuello por subconjunto de camélidos. Table 5. Distribution of neck positions by camelid subset.

\begin{tabular}{|c|c|c|c|c|c|c|}
\hline $\begin{array}{l}\text { Subconjunto / } \\
\text { angulación de cuello }\end{array}$ & $\begin{array}{c}\text { IA } \\
\text { (2 patas) }\end{array}$ & $\begin{array}{c}\text { IB } \\
\text { (3 patas) }\end{array}$ & $\begin{array}{c}\text { IC } \\
\text { (4 patas) }\end{array}$ & $\begin{array}{l}\text { ID } \\
\text { (5 patas) }\end{array}$ & $\begin{array}{c}\text { IE } \\
\text { (6 patas) }\end{array}$ & $\begin{array}{c}\mathrm{IF} \\
\text { (7 patas) }\end{array}$ \\
\hline$\geq 64^{\circ}$ & & & 1 & & & \\
\hline $65^{\circ}-74^{\circ}$ & & & 1 & & & \\
\hline $75^{\circ}-84^{\circ}$ & 1 & 1 & 6 & & & \\
\hline $85^{\circ}-94^{\circ}$ & 12 & 8 & 35 & 1 & 1 & 1 \\
\hline $95^{\circ}-104^{\circ}$ & 2 & 3 & 23 & 1 & & \\
\hline $105^{\circ}-114^{\circ}$ & & 3 & 24 & 2 & & \\
\hline $115^{\circ}-124^{\circ}$ & 1 & 3 & 31 & 1 & & \\
\hline $125^{\circ}-134^{\circ}$ & & 2 & 11 & & & \\
\hline $135^{\circ}-144^{\circ}$ & & & 10 & & & \\
\hline $145^{\circ}-154^{\circ}$ & & & 4 & & & \\
\hline $155^{\circ}-164^{\circ}$ & & & 3 & & & \\
\hline $165^{\circ}-174^{\circ}$ & & & 1 & & & \\
\hline $175^{\circ}-180^{\circ}$ & & & 13 & & & \\
\hline Indeterminado & & 1 & 9 & 1 & & \\
\hline Total & 16 & 21 & 172 & 6 & 1 & 1 \\
\hline
\end{tabular}




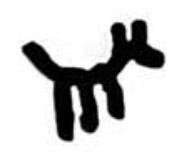

A

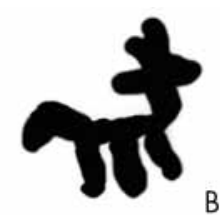

B

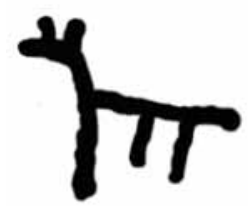

c

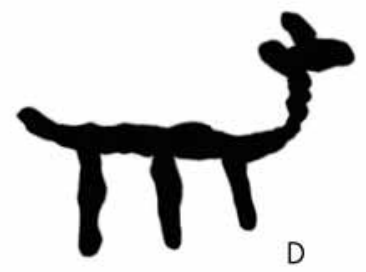

$\mathrm{E}$

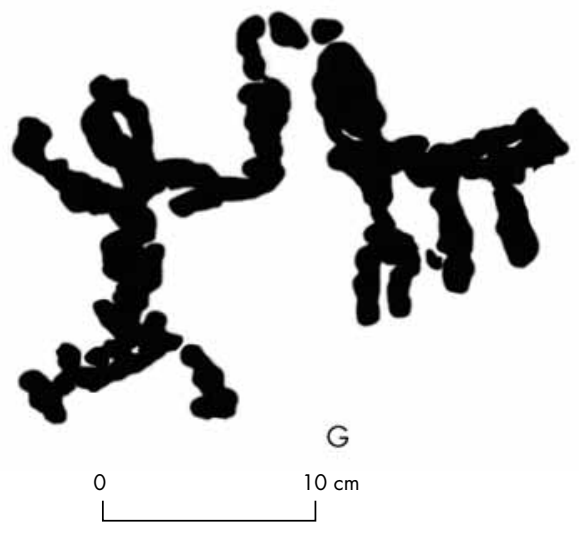

Figura 4. Camélidos lineales con tres extremidades: a, d, e y f) Los Mellizos; b y c) Las Burras; g) Quebrada Lucumán.

Figure 4. Line-drawn camelids with three extremities: $a, d$, e and f) Los Mellizos; b and c) Las Burras; g) Quebrada Lucumán.

En los surcos hay también una cierta variabilidad que viene dada por un predominio de surcos lineales continuos, registrándose un caso de lineal continuo y areal (Tabla 4). Los atributos métricos son homogéneos, pero mayores al conjunto anterior (Tabla 4).

En las escenas, solo en dos casos se reconoce una composición que sugiere pastoralismo $(9,1 \%)$, con un tercero poco claro (fig. 4g). Ambos animales se asocian a angulaciones de cuello de $92^{\circ}$, uno con técnica lineal continua y otro discontinua. Por sobre ello, 17 (80,9\%) casos comparten panel ya sea con antropomorfos u otros camélidos.

Un elemento a destacar en este subconjunto es la presencia de un camélido con sus patas bisulcas, ${ }^{2}$ con un cuello angulado en $92^{\circ}$ y un surco lineal continuo (fig. 4g).

En resumen, si bien el subconjunto presenta un importante grado de homogeneidad, es más variable que el grupo descrito anteriormente, lo que es producto de la mayor dispersión que se observa en los ángulos de cuellos. De hecho, las estrategias de representación de los camélidos se reparten por todas las diferentes angulaciones presentes en este subconjunto, así como de las técnicas registradas, con una menor frecuencia de escenas de pastoralismo, aunque sus totales absolutos son igualmente bajos en ambos conjuntos. El único caso discordante sería el camélido con pata bisulca, pues su constitución visual se diferencia del resto, no obstante compartir una serie de otros atributos. Finalmente, es interesante que en términos métricos este subconjunto es más homogéneo y con valores un poco más altos que el anterior.

Subconjunto IC: Camélidos de cuatro extremidades

Corresponde al grupo más numeroso de la muestra con un total de 172 ejemplares y se asocia a una mayor variabilidad interna que todos los otros subconjuntos, no obstante mantener un cierto grado de homogeneidad (fig. 5). Se mantiene la tendencia a representar recurrentemente cabeza y colas y, en menor medida, orejas (Tabla 4), aunque en 20 casos $(11,6 \%)$ no fue posible reconocer de forma clara su presencia o ausencia. Estos tres elementos están presentes en 119 casos (69,2\%). La mayor heterogeneidad de este conjunto se observa en que el diseño básico de los camélidos se da por animales con colas y orejas hacia arriba con una baja recurrencia (30,3\%), seguida por orejas arriba y cola horizontal (11,6\%) (Tabla 4).

Las angulaciones de cuello son también muy variables, con una concentración en los rangos de $80^{\circ}-99^{\circ}$ y $100^{\circ}-119^{\circ}$ (31, $4 \%$, cada uno), con una leve concentración entre $85^{\circ}-94^{\circ}(\mathrm{N}=35,20,3 \%)$ y $115^{\circ}-124^{\circ}(\mathrm{N}=31 ; 18 \%)$ (Tabla 5). Al considerar la relación entre las angulaciones y las presencias de los elementos constituyentes del camélido, no se reconoce patrón alguno, aunque se observa que la ausencia de colas y cabezas se distribuye homogéneamente entre los ejemplares con angulaciones de cuello entre $90^{\circ}$ y $120^{\circ}$, lo que es esperable, pues acá se concentra la mayor cantidad de ejemplares.

La conformación de los surcos es menos variada que el aspecto anterior, con un predominio del surco 

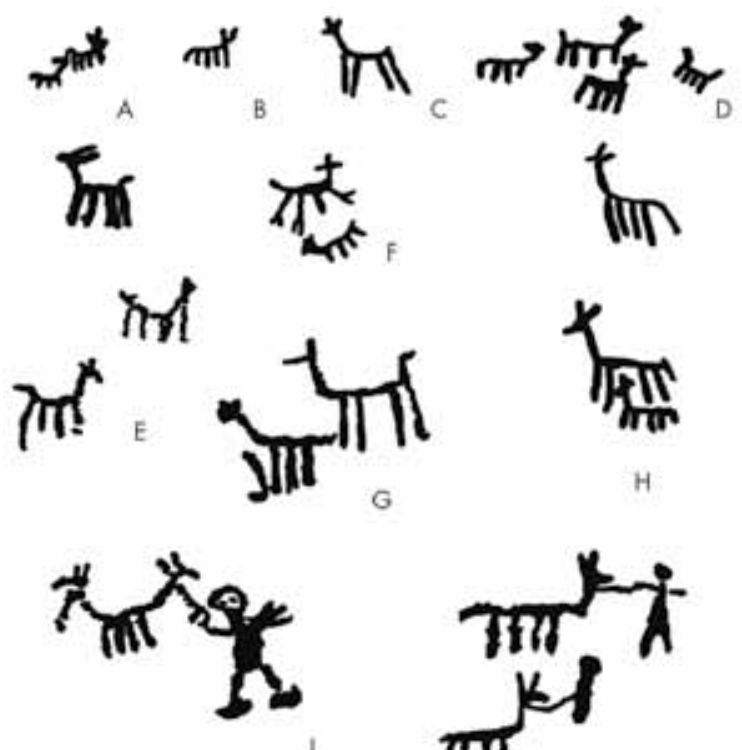

I
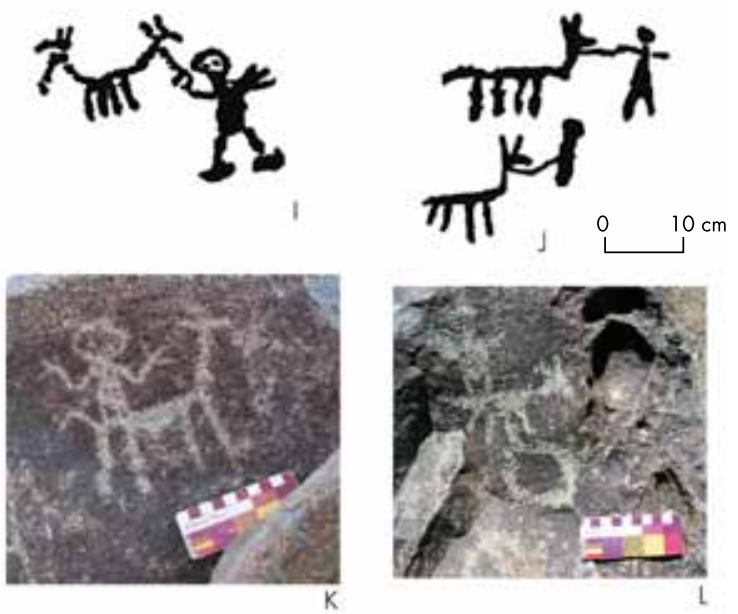

Figura 5. Camélidos lineales con cuatro extremidades: a, b, f, i) Los Mellizos; c) Olla Rota; d y 1) La Junta; e) La Bellaca; g, h y k) El Maitén de las Burras; j) Pichicavén.

Figure 5. Line-drawn camelids with four extremities: $a, b, f$, and i) Los Mellizos; c) Olla Rota; d) and l) La Junta; e) La Bellaca; g, $b$ and k) El Maitén de las Burras; j) Pichicavén.

lineal continuo y un bajo registro de lineal continuoareal (Tabla 4), sin que se observe una relación entre técnicas y angulaciones.

Es interesante hacer notar que dentro del conjunto de camélidos lineales discontinuos, se presenta una alta cantidad de ejemplares sin orejas ( $\mathrm{N}=17,34,7 \%)$, concentrando casi todas las ausencias de los camélidos de cuatro patas $(77,3 \%)$, pero sin una relación con las angulaciones de los cuellos.

En términos métricos, y no obstante la variabilidad reconocida, los camélidos de este subconjunto son bastante homogéneos y con valores similares al subconjunto anterior (Tabla 4).

En términos de conformación de escenas, en 14 casos se reconoce una composición que sugiere pastoralismo, con otros cinco casos posibles, pero poco claros (fig. $5 \mathrm{j}$ ). Todas estas escenas se distribuyen entre los cuellos con angulaciones entre $80^{\circ}$ y $130^{\circ}$. Se presentan las tres técnicas y en relación con sus frecuencias esperadas. Por sobre esto, en 110 bloques se reconocen asociaciones con antropomorfos (63,9\%), y en 140 se asocian a otros camélidos (81,4\%).

Finalmente, otros aspectos interesantes de este subconjunto son, primero, la presencia de individuos con patas bisulcas ( $\mathrm{N}=3$ ) (fig. 5f), todos los cuales fueron elaborados en técnica lineal continua y con angulaciones de $92^{\circ}, 96^{\circ}$ y $124^{\circ}$, respectivamente. Segundo, la representación de camélidos con cargas en sus lomos $(\mathrm{N}=2)$, elaborados con técnica lineal continua y lineal continua/ areal, en cada caso, y angulaciones de cuello de $90^{\circ} \mathrm{y}$ $120^{\circ}$, respectivamente. Tercero, tres escenas de montas asociadas a técnicas lineal continua areal $(\mathrm{N}=2)$ y una a lineal continua, con angulaciones de cuello respectivas de $110^{\circ}, 170^{\circ}$ y $124^{\circ}$ (figs. $5 \mathrm{k}, 1$ ).

En resumen, este subconjunto constituye la entidad más variada de representación de camélidos, lo que es esperable a partir de la alta cantidad de ejemplares que lo componen. Sin embargo, tras esa variabilidad se mantiene una cierta homogeneidad que le entrega un aire de familia, siendo destacable que la mayor variabilidad se da a nivel de los camélidos con una técnica del tipo lineal discontinuo.

En términos de características de las representaciones, destaca en este subconjunto la presencia de tres agrupaciones diferentes: a) escenas de monta, donde el cuadrúpedo sobre el que se establece la figura humana recuerda los rasgos de un camélido; b) escenas de camélidos cargados, donde un bulto se reconoce sobre el lomo del camélido, y c) escenas de pastoralismo, correspondientes a humanos asociados a camélidos, interactuando a través de lazos y donde en ocasiones los camélidos se encuentran en hilera (se incluyen en este conjunto algunos ejemplares con patas bisulcas). A pesar de la alta variabilidad representacional de este conjunto, las escenas de pastoralismo tienden a relacionarse con angulaciones de cuello cercanas a los $90^{\circ}$, las que se reiteran también en alguna escena de monta.

Finalmente, donde se observa la mayor variabilidad escénica y de constitución de estos camélidos es en aquellos que presentan angulaciones en sus cuellos entre $\operatorname{los} 120^{\circ}$ y $180^{\circ}$.

Subconjunto ID: Camélidos de cinco extremidades

Presenta una menor frecuencia que los subconjuntos anteriores, al estar constituido solo por seis ejemplares, los que son muy homogéneos entre si, tal como lo demuestra el hecho que todos presentan cabeza, oreja y cola (figs. $6 \mathrm{a}$ y b), predominando el diseño de animales con colas hacia abajo y orejas hacia arriba. 

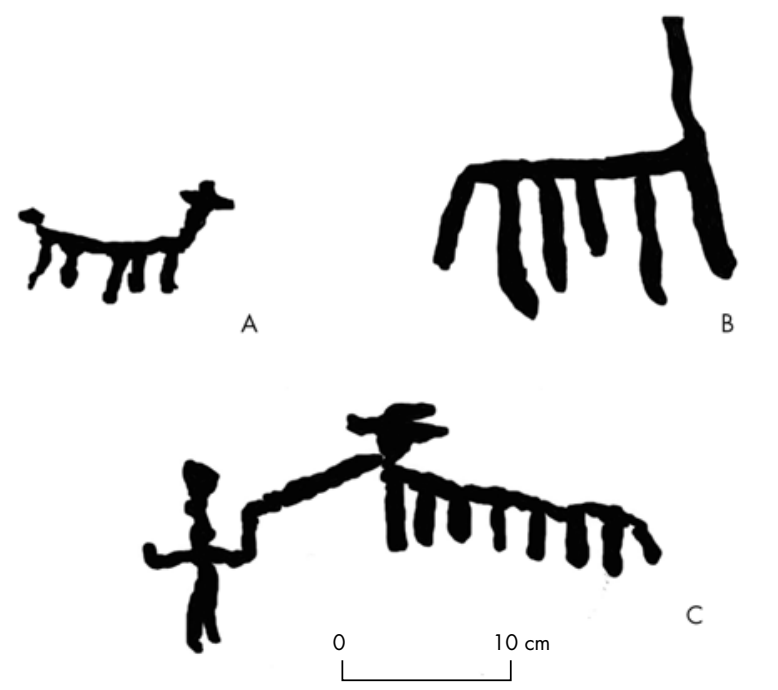

Figura 6. Camélidos lineales con más de cuatro extremidades: a) Los Mellizos, b) Pichicavén y c) Las Burras.

Figure 6. Line-drawn camelids with more than four extremities. a) Los Mellizos, b) Pichicavén and c) Las Burras.

Las angulaciones de los cuellos muestran una mayor variabilidad, con un predominio de aquellas entre $101^{\circ}$ y $120^{\circ}(\mathrm{N}=3 ; 50 \%)$, más específicamente entre $105^{\circ}$ y $114^{\circ}(\mathrm{N}=3 ; 50 \%)$ (Tabla 5). Obviamente, en términos de composición de elementos, estos camélidos comparten todos sus rasgos no obstante la variabilidad en los ángulos de los cuellos.

En la técnica predominan los surcos lineales continuos con un caso de areal-lineal continuo (Tabla 4), correspondiente este último al ejemplar con un cuello angulado en $90^{\circ}$. Métricamente se mantiene una homogeneidad con valores un poco más altos que los conjuntos anteriores, pero con una mayor desviación estándar debido a un ejemplar que se diferencia en sus atributos métricos de todo el resto, pero que no se segrega en términos de composición.

No hay escenas de pastoralismo en este subconjunto. En seis casos (85,7\%) comparten panel con otros camélidos y en cuatro, con antropomorfos $(57,1 \%)$.

En resumen, este conjunto de camélidos, si bien pequeño, es altamente homogéneo, tanto en términos compositivos, como métricos, existiendo dos casos que se tienden a segregar: uno que es el camélido con un cuello de $90^{\circ}$ y que se diferencia en los atributos de composición visual y otro, por sus atributos métricos y uso de la técnica lineal continua y areal. Este último caso es clara y totalmente divergente del resto de estos cuadrúpedos, lo que se refrenda en la misma manera de representar al camélido, distanciándose de todo el conjunto de ejemplares reconocidos en el valle (fig. 2).
Destacamos que no hay escenas de pastoralismo y la baja cantidad de angulaciones de cuello de $90^{\circ}$.

Subconjunto IE: Camélidos de seis extremidades

Incluido en esta categoría, aunque no constituye en sí un subconjunto, comprende un solo ejemplar con cabeza y oreja (dispuesta hacia atrás), sin que se pueda distinguir de buena manera la presencia de una cola. Tiene un cuello con una angulación de $92^{\circ}$. Técnicamente, el surco es del tipo lineal continuo. Sus atributos métricos son cercanos a los de los otros grupos (Tabla 4).

No se encuentra en una escena de pastoralismo, y comparte espacio en el panel con representaciones antropomorfas y camélidos.

Subconjunto IF: Camélidos de siete extremidades

$\mathrm{Al}$ igual que el subconjunto anterior, es solo un caso definido por la presencia de cabeza, oreja (hacia atrás) y cola (hacia abajo), en que el cuello tiene una angulación de $90^{\circ}$ (fig. 6c). El surco es de tipo lineal continuo y sus atributos métricos son algo mayores a los tradicionales (Tabla 4). Este mayor largo se debe sin duda a la alta cantidad de extremidades que posee el camélido.

A diferencia del caso aislado del subconjunto anterior, este se encuentra en una escena de pastoralismo junto a un antropomorfo, pero no hay otros camélidos presentes en el panel.

\section{Conjunto II: Camélidos no lineales}

Como indicamos, es un conjunto de muy baja representación con solo cuatro ejemplares grabados en un bloque de arte rupestre al interior de la quebrada de Las Burras. Estos camélidos se definen por una composición areal que no se basa en la aplicación de trazos lineales, sino más bien en la creación de volúmenes rellenos que les entregan gracilidad y animación (fig. 7). Esta constitución visual permitió establecer un análisis métrico como el propuesto por Gallardo y Yacobaccio (2005, 2007), reconociéndose para todos los ejemplares valores correspondientes a llamas (Lama glama) (Tabla 6).

\section{CAMÉLIDOS EN EL ARTE RUPESTRE DEL CHOAPA: UNA DISCUSION TIPOLÓGICO-CRONOLÓGICA}

La sistematización que hemos propuesto en las páginas precedentes permite organizar el variado y rico registro de camélidos en el valle del Choapa, y a partir de ello, 
Tabla 6. Atributos métricos camélidos no lineales. Table 6. Metric attributes of camelid representations (not line-drawings).

\begin{tabular}{|c|c|c|c|c|c|}
\hline No figura & Cuerpo (C) & $\begin{array}{c}\text { Patas delanteras } \\
\text { (PD) }\end{array}$ & $\begin{array}{c}\text { Patas traseras } \\
(\mathbf{P T})\end{array}$ & Proposición PT/C & Proporción PD/C \\
\hline 1 & 2,8 & 2,1 & 2,2 & 0,78 & 0,75 \\
\hline 2 & 3,1 & 4 & 3,4 & 1,09 & 1,29 \\
\hline 3 & 2,6 & 2,8 & 2,5 & 0,96 & 1,07 \\
\hline 4 & 4,7 & 3,5 & 2,5 & 0,5 & 0,74 \\
\hline
\end{tabular}

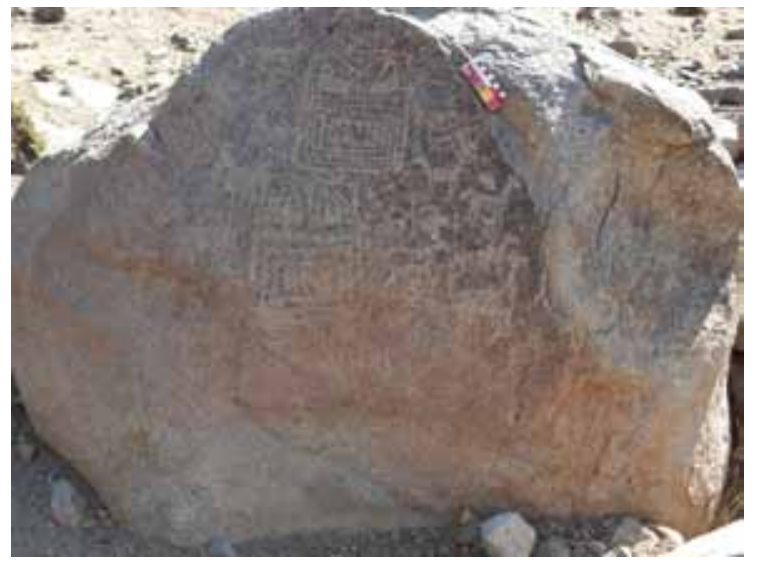

Figura 7. Camélidos no lineales. El Maitén de Las Burras. Figure 7. Camelids, not line-drawn. El Maitén de Las Burras.

establecer una discusión sobre sus asignaciones cronológicas considerando sus atributos intrínsecos, así como escenificaciones. Sin embargo, consideramos importante enfatizar que, no obstante la cantidad y la variedad de camélidos presentes en el primer conjunto -camélidos lineales-, ellos mantienen una homogeneidad visual y métrica que les entrega identidad, sin que se puedan discernir quiebres notables en la representación de estos animales.

Pensamos que una primera aproximación a la discusión cronológica de estos camélidos es a partir de las escenificaciones en las que se encuentran, en particular nos referimos a todas las representaciones que sugieren actividad pastoril (figs. 3d, 4g, 5j, 6c, 8). Todas aquellas escenas donde se establece una interacción de este tipo, ya sea por la presencia de hileras de camélidos laceados, o bien de ejemplares aislados laceados en posición pasiva, proponemos asignarlas al Período Tardío, por cuanto los trabajos zooarqueológicos efectuados en el Choapa han indicado que solo para este tiempo se conoce la presencia de camélidos domesticados (Becker 2004; Troncoso 2004). Este hecho es coherente con el registro material de la Cultura Diaguita, representante poblacional de los períodos Intermedio Tardío (1000-1450 DC) y
Tardío (1450-1530 DC) cuando los restos de camélidos son escasos, no se reconoce infraestructura asociada a corrales y hay una baja movilidad de estas poblaciones, como lo sugiere la nula presencia de bienes foráneos en la zona. En esa línea, la representación de escenas de pastoreo solo puede ser pensada y materializada en la zona durante época inkaica.

Esta asignación implica que dentro de los subconjuntos de camélidos de dos, tres, cuatro y seis patas se incluyen representaciones asignables a este momento, aunque con distintas frecuencias.

En esa línea, consideramos que se debe incluir dentro de este componente de arte rupestre del Período Tardío a todos aquellos camélidos con angulaciones de cuello cercanas a los $90^{\circ}$ (intervalo $80^{\circ}-100^{\circ}$ ). Esto se basa en dos hechos. Primero, que son los camélidos con estas angulaciones los que presentan una mayor frecuencia de representación de escenas de pastoreo. Del total de 20 escenas reconocidas, 13 (65\%) abarcan camélidos con angulaciones de cuello entre los $81^{\circ}$ y $100^{\circ}$ y, más específicamente, hay nueve casos (45\%) en que tales valores están entre los $85^{\circ}$ y $95^{\circ}$. Muy lejanamente le sigue el rango de $101^{\circ}-120^{\circ}$ con cinco casos (25\%). Esto implica que ya superado tal rango, son casi inexistentes las escenas de pastoreo.

Segundo, al igual como ocurre en el Norte Grande, pensamos que estas disposiciones de cuellos en angulaciones próximas a los $90^{\circ}$ recuerdan las descripciones de los camélidos esquemáticos y rígidos asignados a este tiempo (Gallardo \& Vilches 1995, 2001; Vilches \& Uribe 1999; Sepúlveda 2008). En esa línea, si observamos la distribución de esta angulación de cuello $\left(80^{\circ}-100^{\circ}\right)$, vemos que ella proporcionalmente está mayormente representada en el subcojunto IA (Tabla 5), que también alcanza las frecuencias más altas en relación con la presencia de escenas de pastoreo, estando algo menos representado en otros subconjuntos, en los que también se observa una más baja frecuencia de escenas de pastoreo.

Es a partir de tales antecedentes, por tanto, que proponemos que el subconjunto IA, camélidos lineales de dos patas, se adscribiría en su totalidad al Período 
Tardío, tanto por la existencia de escenas de pastoralismo en su interior, como el predominio de angulaciones de cuello en el rango de los $80^{\circ}-100^{\circ}$. A ello se puede agregar el predominio de los surcos lineales continuos, atributo técnico que es compartido con motivos propios a este momento (p. ej., ajedrezados) y que es poco frecuente en momentos previos. La variación que existe en este subconjunto en términos métricos se debería a las estrategias de composición de cada panel y no lo consideramos relevante.

Siguiendo tales propuestas, dividimos el subconjunto IB, camélidos lineales con tres patas, en representaciones propias al Período Tardío y otras de tiempos previos que definiremos a continuación. Las primeras corresponderían tanto a los camélidos que se encuentran en escenas de pastoralismo, como aquellos con angulaciones de cuello en el rango $80^{\circ}-100^{\circ}(\mathrm{N}=10,47,6 \%)$. Como en el caso anterior, en este grupo se observa una alta presencia de surcos lineales continuos y aparece la técnica lineal/ continua/areal, la que hemos asociado de manera exclusiva con este momento (Troncoso 2010). Destaca en este grupo un individuo con patas bisulcas.

El segundo segmento de este subconjunto se define porque sus cuellos exceden angulaciones de $100^{\circ}$ y no se registran escenas de pastoreo. Sugerimos su asociación con los períodos Intermedio Tardío y Tardío de manera genérica, por cuanto: a) presentan una homogeneidad interna tanto con los restantes camélidos de tres patas, como con aquellos del subconjunto IA; b) sus atributos técnicos muestran un predominio de surcos lineales continuos (seis de nueve) y lineal/continuo/areal que es propio a tiempos inkaicos, y c) los rangos de angulaciones de cuello de estos camélidos se tienden a concentrar en el rango $100^{\circ}-120^{\circ}$ (cinco de nueve), espacio donde como vimos anteriormente se dan también camélidos propios de tiempos tardíos. De la misma forma, no pensamos que ellos deban ser adscritos dentro de la categoría del Alfarero Temprano, por cuanto la homogeneidad y la similitud que se establece en sus ámbitos visuales y tecnológicos lleva a pensar en la ausencia de una gran distancia cronológica con los grabados asignados a la Cultura Diaguita. La imposibilidad de segregar entre aquello del Intermedio Tardío y Tardío a partir de los atributos de estos camélidos es algo coherente con la continuidad que se da en los patrones decorativos de la alfarería en tiempos Diaguita preinkaico e inkaico en el Choapa (González 2004; Troncoso et al. 2009).

Un razonamiento similar al anterior efectuamos con el subconjunto ID, camélidos lineales de cinco patas, donde hay un ejemplar que remite a los principios propios del Período Tardío (angulación de cuello de 90) (fig. 4b), mientras que los restantes cinco los asignamos al Período Intermedio Tardío y Tardío por las razones previamente indicadas, pues encontramos angulaciones mayormente entre $100^{\circ}$ y $120^{\circ}$, así como uso de técnica lineal discontinua.

Asignamos también al Período Tardío el único ejemplar del subconjunto IF, camélidos lineales de siete patas, el que presenta todos los rasgos propios a este tiempo: técnica lineal continua, angulaciones de cuello de $90^{\circ}$ y representación en una escena de pastoralismo (fig. 6c). Las dos primeras características están presentes también en el subconjunto IE, camélidos de seis patas, sugiriendo una asignación similar. Considerando lo inusual de estas representaciones pensamos que ambos casos pueden interpretarse como esquematizaciones de hileras de camélidos -es decir, caravanas-, siendo el número de extremidades el elemento que indica la existencia de más de un ejemplar (ver p. ej., fig. 8 para otras posibles escenas caravaneras). Esta propuesta es coherente con la forma de representación del camélido de siete patas y se podría vislumbrar su lógica de reducción en algunas escenas de pastoreo reconocidas en camélidos de dos y cuatro patas.

Mientras todos los subconjuntos anteriores no muestran una gran variabilidad, siendo posible adscribirlos mayormente al Período Tardío, y en menor medida al Intermedio Tardío, la situación cambia de manera importante dentro del subconjunto IC, camélidos lineales de cuatro patas, pues el alto número de ejemplares va de la mano con una mayor variabilidad en su interior.

Un primer grupo de camélidos puede remitirse al Período Histórico Temprano, debido a que ellos se encuentran montados por personajes humanos, pero sus técnicas son similares a las del arte rupestre prehispánico. Los tres casos reconocidos son camélidos de cuatro patas, con angulaciones de cuellos sobre los $120^{\circ}$, uso

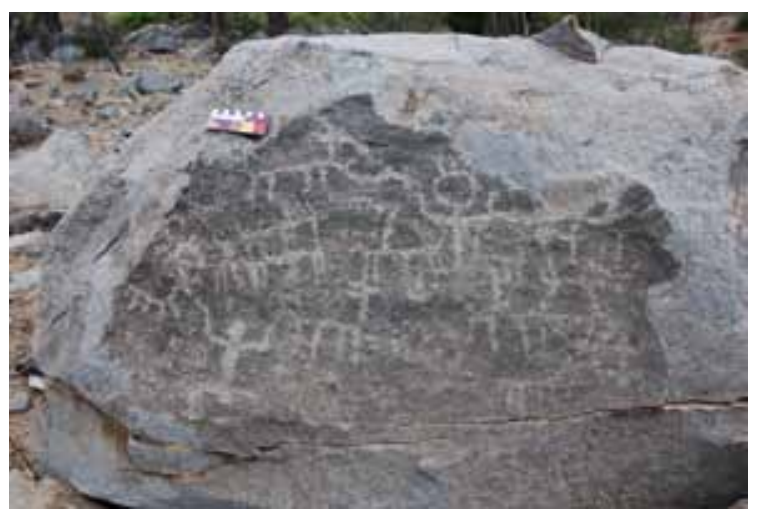

Figura 8. Escena de pastoreo con animales laceados y alineados (¿caravana?). Pichicavén.

Figure 8. Herding scene with roped animals in a line (caravan?). Pichicavén. 
de técnica lineal continua ( $\mathrm{N}=1$ ), y lineal/continua/areal $(\mathrm{N}=2)$. Estos atributos son significativos, pues no solo muestran una continuidad técnica con los camélidos de los períodos Intermedio Tardío y Tardío, sino que ratifican la cronología de los últimos dada la cercanía visual que presentan en aspectos como el uso de técnica lineal/continua/areal y la presencia de patas bisulcas.

Si bien estos animales montados remiten a las convenciones visuales de los camélidos del Choapa, su configuración recuerda la noción de dualidad camélido/caballo (Gallardo et al. 1990; Martínez 2009), pues mientras su visualidad hace referencia al primer aspecto, su escenificación se relaciona con el segundo.

Pensamos que adscrito también a tiempos históricos -pero posiblemente algo más tardíos que las escenas de montas- es otro cuadrúpedo que asemeja más bien a un caballo que un camélido, y se encuentra laceado por un personaje antropomorfo que se diferencia también en sus patrones constructivos de los motivos humanos previos (fig. 5i). Pensamos en una data más tardía pues en ella el animal adquiere una visualidad más de caballo, mostrando una separación con lo conocido previamente, idea que ya avanzaron algunos autores (Arenas \& Martínez 2009; Martínez 2009).

Un segundo conjunto, y de baja representación, se asociaría al Período Tardío y correspondería a aquellos camélidos que están en escenas de pastoralismo, o bien que se encuentran con sus lomos cargados, así como aquellos con angulaciones de cuello entre $80^{\circ}$ y $100^{\circ}$ y con una técnica del tipo lineal continua o lineal/continua/areal (p. ej., figs. 5a, e, g, h, j). Estos son bastante menores en proporción a los otros subconjuntos, lo que es coherente con la amplia variabilidad que presenta este grupo. En efecto, en este conjunto encontramos nuevamente que se da una cercana relación entre estos dos atributos, pues de los 14 casos con escenas de pastoralismo, ocho $(57,1 \%)$ se encuentran en el rango de cuello entre $81^{\circ}$ y $100^{\circ}$, seguido cercanamente por cuatro $(28,6 \%)$ casos restantes en el rango siguiente $\left(100^{\circ}-120^{\circ}\right)$ (Tabla 7).

Por sobre estos dos conjuntos se encuentra una gran cantidad de camélidos con angulaciones de cuello sobre los $100^{\circ}$ y en los que se encuentran técnicas lineales continuas y discontinuas, así como una baja presencia de escenas de pastoralismo (p. ej., figs. 5a, c, f). Pensamos que es en este conglomerado donde se distribuye, por un lado, un conjunto de camélidos asignados al Período Tardío dado por sus atributos técnicos (lineal/continuo/ areal) y, por otro, animales propios al Intermedio Tardío y que se definen más bien por el predominio de técnicas lineales discontinuas.

$\mathrm{Al}$ respecto, se podrá observar la ausencia clara de camélidos propios al Período Alfarero Temprano, no
Tabla 7. Distribución de escenas de pastoreo en asociación a subconjuntos de camélidos.

Table 7. Distribution of herding scenes associated with camelid subsets.

\begin{tabular}{|r|c|c|c|c|}
\hline $\begin{array}{c}\text { Escenas } \\
\text { pastoralismo }\end{array}$ & $80^{\circ}-100^{\circ}$ & $100^{\circ}-120^{\circ}$ & $\mathbf{1 2 0}^{\circ}-140^{\circ}$ & Total \\
\hline IA (2 patas) & 2 & 1 & & 3 \\
\hline IB (3 patas) & 2 & & & 2 \\
\hline IC (4 patas) & 8 & 4 & 2 & 14 \\
\hline ID (5 patas) & & & & 0 \\
\hline IE (6 patas) & & & & 0 \\
\hline IF (7 patas) & 1 & & & 1 \\
\hline Total & 13 & 5 & 2 & \\
\hline
\end{tabular}

obstante las propuestas clásicas sobre el arte rupestre del Norte Semiárido que han tendido a enfatizar tal asociación. Más allá de las críticas que expusimos previamente, lo cierto es que no encontramos rasgo alguno que permita de manera directa establecer una asociación entre camélidos y tal momento de la prehistoria local. Muy por el contrario, los atributos de los camélidos presentes sugieren una adscripción mayormente a los períodos Intermedio Tardío y Tardío, situación que es coherente con cinco aspectos.

Primero, que todos los camélidos de tipo lineal mantienen una similitud y un aire de familia, refrendado por sus atributos métricos, que hacen difícil pensar en una amplia extensión cronológica de este motivo a lo largo de la prehistoria, pues son muy homogéneos entre sí.

Segundo, en términos de composición, la inserción de los camélidos tampoco es muy divergente al interior de la muestra de estudio, pues o bien ellos están en escenas de pastoreo, o bien se dispersan aislados o en conjuntos dentro de los bloques rupestres, sin que se observe una escenificación de actividades de cacería y que abra las puertas a otras configuraciones representacionales.

Tercero, los distintos conjuntos de camélidos comparten espacios reiteradamente en los bloques de arte rupestre y, como ya vimos, ellos no muestran mayores diferencias de pátinas dentro del panel como para sugerir grandes distancias cronológicas.

Cuarto, las escasas superposiciones muestran una cercanía temporal de las representaciones y el predominio de disponer camélidos sobre otros motivos lleva a pensar que su construcción se da en los momentos finales de intervención de los bloques rupestres. En los pocos casos en que estos están bajo otros motivos (dos de 16), se les superponen otros camélidos similares. Todo lo anterior, por tanto, sugiere fuertemente que 
estos motivos son más bien propios de los momentos finales de la secuencia de producción de arte rupestre en el Choapa.

Quinto, los camélidos del Período Histórico Temprano guardan similitudes formales y técnicas con los de tiempos prehispánicos, lo que sugiere que entre ambos tipos de representación no hay una amplia distancia cronológica.

En este contexto, si bien no rechazamos de plano la presencia de camélidos del Alfarero Temprano, se requiere mayor evidencia para su reconocimiento, aunque por los atributos pensamos que de existir, ellos deberían encontrarse en el subconjunto de camélidos de cuatro patas con angulaciones entre los $120^{\circ}$ y $180^{\circ}$, pues en tal rango no solo son escasas las escenas de pastoreo, sino también es donde está la mayor variabilidad de representación.

A su vez, estos resultados son coherentes con el contexto general del arte rupestre en el valle del Choapa, donde los últimos estudios han mostrado que el grueso de las representaciones se asocian a los períodos Intermedio Tardío y Tardío, replicándose en los grabados patrones de simetría e iconografía reconocida en la alfarería de tales momentos (González 2011; Troncoso 2011; Armstrong 2012). ${ }^{3}$

En síntesis, estos resultados nos permiten categorizar tres grandes agrupaciones de camélidos para la zona (Tabla 8).

Primero, camélidos de tiempos históricos $(\mathrm{N}=5)$, que se definen básicamente por su representación en escenas de monta, correspondiendo a cuadrúpedos de cuatro patas que, en ocasiones, presentan patas bisulcas y donde se da una técnica de producción lineal continua y lineal continua/areal. Todos los animales presentan cabeza, orejas y cola. Las primeras se disponen mayormente de forma horizontal $(\mathrm{N}=4)$, las orejas hacia arriba $(\mathrm{N}=3)$ y con las colas distribuidas de igual manera hacia arriba, abajo y en horizontal.
Segundo, camélidos del Período Tardío (N=100), donde, por un lado, encontramos los cuatro camélidos no lineales, los que se adscriben a este momento debido a su identificación como llamas (Lama glama). Por otro, en los camélidos lineales ( $\mathrm{N}=96)$, encontramos representaciones de dos, tres, cuatro, cinco, seis y siete patas, las que se definen por presentar angulaciones de cuello entre los $80^{\circ}$ y $100^{\circ}$, con una importante concentración alrededor de los $90^{\circ}$. Se encuentran algunos pocos ejemplares con patas bisulcas y hay un uso de técnicas lineal continua, lineal/continua/areal y, en menor cantidad, lineal discontinua. Se encuentran en este conjunto escenas de pastoralismo, o bien de animales con bultos en sus lomos.

La mayor parte de estos camélidos presentan cabeza $(\mathrm{N}=88,90,7 \%)$, al igual que colas $(\mathrm{N}=82,84,5 \%)$; las orejas se representan en menor cantidad ( $N=69,71,1 \%)$. Si bien las cabezas se disponen de manera horizontal, hacia arriba y hacia abajo, hay un claro predominio de la primera posición ( $\mathrm{N}=70,79,5 \%)$; en contraposición, las colas se distribuyen de manera homogénea en las diferentes posiciones (adelante, arriba, atrás). Para el caso de las orejas, hay un predominio de su disposición hacia arriba y hacia atrás ( $\mathrm{N}=36$ y 27 , respectivamente). Lo anterior muestra una gran heterogeneidad en la producción de los rasgos menores de estos camélidos, sin que se observe un patrón en la relación posición de colas, orejas y cabeza, situación que se reitera al considerar únicamente la configuración de los camélidos en escenas de pastoreo.

Un tercer grupo se remite al Período Intermedio Tardío ( $\mathrm{N}=22$ ), el que está constituido por camélidos de cuatro patas que tienen angulaciones de cuello sobre los $100^{\circ}$, alcanzando en algunos casos los $180^{\circ}$. No se reconocen individuos con patas bisulcas y hay un uso de las técnicas lineal discontinua y, en muy menor medida, lineal continua. Se tiende a representar a los animales

Tabla 8. Frecuencia de tipos de camélidos lineales por período cronológico.

Table 8. Frequency of types of line-drawings of camelids by chronological period.

\begin{tabular}{|c|c|c|c|c|c|c|c|c|}
\hline & $\begin{array}{c}\text { IA } \\
\text { (2 patas) }\end{array}$ & $\begin{array}{c}\text { IB } \\
\text { (3 patas) }\end{array}$ & $\begin{array}{c}\text { IC } \\
\text { (4 patas) }\end{array}$ & $\begin{array}{c}\text { ID } \\
(5 \text { patas })\end{array}$ & $\begin{array}{c}\mathrm{IE} \\
\text { (6 patas) }\end{array}$ & $\begin{array}{c}\text { IF } \\
\text { (7 patas) }\end{array}$ & Total & $\%$ \\
\hline PIT & & & 21 & & & & 21 & $9,7 \%$ \\
\hline PIT-PT & & 9 & 79 & 3 & & & 91 & $41,9 \%$ \\
\hline PT & 16 & 12 & 65 & 1 & 1 & 1 & 96 & $44,3 \%$ \\
\hline Histórico & & & 5 & & & & 5 & $2,3 \%$ \\
\hline No determinado & & & 2 & 2 & & & 4 & $1,8 \%$ \\
\hline Total & 16 & 21 & 172 & 6 & 1 & 1 & 217 & $100 \%$ \\
\hline
\end{tabular}

$(\mathrm{PIT}=$ Período Intermedio Tardío; PIT-PT $=$ Período Intermedio Tardío-Tardío; PT = Período Tardío $)$.

$(P I T=$ Late Intermediate Period; PIT-PT = Late Intermediate-Late Period; $P T=$ Late Period $)$. 
con colas $(\mathrm{N}=20,90,9 \%)$, cabezas $(\mathrm{N}=17,77,3 \%)$ y, con menos frecuencia, orejas $(\mathrm{N}=14,63,6 \%)$. Las cabezas se disponen casi exclusivamente en horizontal ( $\mathrm{N}=15,88,2 \%)$, las orejas hacia arriba $(\mathrm{N}=9,64,3 \%)$ y las colas de manera horizontal ( $\mathrm{N}=20,100 \%)$, lo que implica un predominio de camélidos con cabezas y colas horizontales $(\mathrm{N}=14)$.

Finalmente, se agrupan otros camélidos en una categoría genérica Intermedio Tardío y Tardío (N=91), por cuanto los rasgos de cada uno de ellos no fueron lo suficientemente diagnósticos para lograr establecer una separación tajante, reproduciendo la dinámica de continuidad observada en los conjuntos visuales plasmados en la alfarería de los períodos Intermedio Tardío y Tardío del Choapa (González 2004). De la misma manera, se dejaron cuatro ejemplares como indeterminados.

\section{CAMÉLIDOS, ESPACIO Y PREHISTORIA EN EL VALLE DEL CHOAPA}

La anterior formulación tipológica y cronológica de los camélidos puede complementarse integrando estos resultados dentro de las dinámicas espaciales de la prehistoria, aspecto que, por una parte, permite fortalecer nuestra proposición y, por otra, discutir la lógica de estos motivos a la luz de tales antecedentes.

Si observamos la representación espacial de los camélidos dentro de los patrones de ocupación del valle de Illapel y el vecino valle de Chalinga, encontramos una interesante relación. Por un lado, y como ya se observó, a nivel macroespacial los camélidos se encuentran mayormente representados en el valle de Illapel que en el valle de Chalinga (Tabla 2), situación que es paralela con el hecho de que los registros de la vida social prehispánica en ambos valles han mostrado un fuerte ocupación de la Cultura Diaguita, en contraposición a un escaso uso del valle de Chalinga, donde sus asentamientos son de carácter más restringido, a manera de enclaves, mostrando una pervivencia de grupos de tradición alfarera temprana hasta tiempos históricos (Pavlovic 2004; Troncoso 2004; Troncoso et al. 2009).

En ese contexto, la asignación mayormente hacia los períodos Intermedio Tardío y Tardío de los camélidos es coherente con las dinámicas e intensidades de ocupación reconocidas para cada espacio, pues su registro es más frecuente en Illapel que en Chalinga. De hecho, si los camélidos fueran mayormente tempranos debería esperarse al menos en Chalinga una recurrencia como la de Illapel.

Por otro lado, a nivel microrregional, la situación es aun más diagnóstica, por cuanto en el valle de Illapel los camélidos se representan con mayor fuerza en su curso superior, que en el medio e inferior (Tabla 2). Esta situación es coherente con el emplazamiento en tal espacio de uno de los principales asentamientos de las comunidades diaguita-inkaicas en el valle de Illapel, el sitio Césped 3, que ha sido interpretado como un espacio desde el cual se establece un circuito de movilidad de recursos hacia la vertiente oriental de los Andes y en el que se han recuperado falanges de llamas cargueras, siendo posible pensar en la presencia de caravaneo (Troncoso et al. 2004). La alta proliferación de camélidos en tal espacio es, por tanto, coherente con las dinámicas de vida social establecidas en tiempos inkaicos por las comunidades locales.

En el caso de Chalinga, si bien son pocos los bloques con camélidos, es interesante hacer notar que ellos aparecen mayoritariamente en la cuenca media (Tabla 2), específicamente en los espacios próximos al área de Ranqui, lugar donde se dispone el principal asentamiento Diaguita-Inka de Chalinga (Ranqui 5) y en el que están presentes todos los tipos de camélidos asociados a este momento. Alejándose de este espacio los motivos de camélidos comienzan a desaparecer (Tabla 2). La menor frecuencia de representación se asociaría a una menor intensidad de la ocupación Diaguita-Inka en Chalinga, pero manteniendo el patrón de asociación de estas imágenes con el principal sitio Diaguita-Inka del valle.

Vemos entonces que las cronologías y las frecuencias reconocidas para los camélidos en el arte rupestre son coherentes con el comportamiento espacial de este tipo de registro, así como con los patrones de emplazamiento y dinámica espacial de las comunidades del Intermedio Tardío y Tardío. De hecho, una ampliación de la mirada hacia el restante registro rupestre en ambos espacios muestra también una mayor cantidad de grabados rupestres asignables a tiempos tardíos (p. ej., clepsidras, ajedrezados, máscaras escaleradas) (González 2011).

Esta mayor frecuencia de camélidos en el arte rupestre de la cuenca superior del río Illapel ya había sido reconocida por Castillo (1991), quien la había interpretado en relación con una mayor cantidad de camélidos poblando tales espacios. De esta manera, el aumento gradual que observaba en el número de representaciones de camélidos desde tierras bajas hacia tierras altas era coherente con el incremento de estos animales en el paisaje. Nuestros análisis no apoyan tal idea por dos razones. La primera es la escasa evidencia para sugerir una mayor población de camélidos en tierras altas en Illapel en comparación a tierras bajas; si bien ello es hoy en día real, es al menos en parte producto de la acción de las comunidades campesinas contemporáneas. La segunda, es que si tal hipótesis fuera correcta, debería encontrarse un patrón similar en el vecino valle de Chalinga, situación que no se da, lo 
que sugiere, por tanto, que la dinámica de representación de los camélidos se articula con otros aspectos, donde a nuestro entender la centralidad de los imaginarios sociales, las prácticas de movimiento interregional y el registro de ocupaciones Diaguita y Diaguita-Inka son centrales para su comprensión.

Del mismo modo, nuestros resultados son coherentes con las dinámicas establecidas entre las comunidades humanas y los camélidos. En efecto, mientras solo se ha reconocido para época inkaica la presencia de camélidos domesticados, el registro zooarqueológico de tiempos previos se define por una casi nula presencia de restos en el Alfarero Temprano, una baja cantidad en el Intermedio Tardío y un alto registro en época inkaica (Becker 2004).

Más allá de los posibles problemas tafonómicos que podrían afectar la muestra, lo cierto es que los modelos sociales para comprender los períodos Alfarero Temprano e Intermedio Tardío en el Choapa son coherentes con una escasa centralidad de los camélidos en la vida social de estas poblaciones (Troncoso 1999, 2004; Pavlovic 2004; Troncoso et al. 2009). Mientras en el caso de las sociedades Alfareras Tempranas se observa un modo de vida móvil con cultígenos a baja escala como la quínoa (Chenopodium quinoa), su patrón de asentamiento se asocia de preferencia a tierras altas en relación con espacios de cultivo de este cereal, con una baja existencia de avistaderos de caza, mayormente reconocidos en el valle de Chalinga (Pavlovic 2004).

El caso del Intermedio Tardío se caracteriza más bien por una dinámica campesina con bajas tasas de movilidad, como lo demuestra la ausencia de material foráneo a la zona, y donde la dinámica productiva es nuevamente hacia el ámbito de los cultivos por sobre otra cosa, no obstante la evidencia de caza de camélidos (Troncoso 1999). En ese contexto nos parece interesante señalar que de acuerdo a estas lógicas de modo de vida, la domesticación de camélidos no se constituye en un acto esencial para la vida social y dinámica de estas poblaciones, por lo que su ausencia es coherente con el registro material.

De esta manera, la sistematización que hemos propuesto para los camélidos se integra de manera lógica con la dinámica del registro arqueológico restante y los procesos sociales que han sido propuestos para la zona.

\section{CONCLUSIONES: DEL CHOAPA AL NORTE SEMIÁRIDO}

Los resultados alcanzados a partir de este primer intento de sistematización y discusión cronológico-cultural de las representaciones de camélidos en el valle del Choapa sugieren una realidad muy diferente a lo clásicamente propuesto para el arte rupestre del Norte Semiárido, indicando una mayor intensidad en la creación de grabados de estos animales para los momentos finales de la historia prehispánica. La aparición de escenas de pastoralismo, la similitud de los camélidos en estas escenas con otros representados aisladamente y el registro de camélidos esquemáticos rígidos, son parte de las evidencias propuestas para una asignación a los períodos Intermedio Tardío y Tardío de un número importante de estos petroglifos.

Estos resultados dan cuenta de una coherencia entre el arte rupestre y el restante registro arqueológico conocido en el valle del Choapa, en que un tema central que ha sido abordado es el impacto de la incorporación de este territorio al Tawantinsuyu, proceso que implicó una importante modificación en las relaciones sociales y culturales de producción al interior de las comunidades Diaguita (Troncoso 2004). El aumento en las representaciones de camélidos, la ilustración de escenas de pastoreo sumado a su concentración en un espacio asociado al tráfico de bienes hacia la vertiente oriental de los Andes, muestran cómo estas transformaciones en los ámbitos infraestructurales fueron de la mano con una modificación tanto en los discursos visuales como en los imaginarios de las comunidades locales, anclando en la roca la materialidad y la inmaterialidad de tales cambios.

Asimismo, se observa cómo la dinámica espacial intravalle e intervalle de producción/consumo de arte rupestre es sensible a los contextos sociales que la definen, mostrando una heterogeneidad espacial que recién se está comenzando a explorar. Esta variabilidad pensamos que se da no solo dentro del Choapa al momento de comparar lo que son los valles de Illapel y Chalinga, sino que posiblemente ocurre en valles vecinos, tal como el Limarí, donde mientras en las tierras bajas los camélidos son relativamente escasos (Valle El Encanto, San Pedro de Quiles) (Ampuero \& Rivera 1971; Niemeyer \& Castillo 1996; Troncoso et al. 2008), en las tierras altas del valle de Hurtado se observa una mayor popularización de su registro (Ballereau \& Niemeyer 1999).

En este contexto, no solo es necesario repensar las asignaciones cronoculturales y dinámicas del arte rupestre, y de las representaciones de camélidos en los valles más septentrionales del Norte Semiárido, sino también evaluar nuestra propuesta tipológico-cronológica en estos espacios. Sin embargo, una primera revisión a las referencias de camélidos para el valle del Limarí muestra un panorama similar al observado en Choapa (Ballereau \& Niemeyer 1999; García 2005). 
A su vez, se hace urgente revaluar categorías como el Estilo La Silla, que si bien ha sido reconocido como propio del Período Alfarero Temprano usando a los camélidos como un elemento diagnóstico, adolece de análisis visuales específicos de estos animales como para sugerir una homogeneidad.

No obstante ello, el reconocimiento de posibles escenas de interacción entre humanos y animales domesticados en algunos soportes del sitio tipo La Silla (Niemeyer \& Ballereau 1998: 291, 315), son un aliciente para pensar en que en este conjunto se incluyen producciones realizadas al menos en tiempos posteriores al Alfarero Temprano, idea que es reforzada al observar entre los motivos no figurativos el motivo Chacras (sensu Niemeyer \& Ballereau 1986, lám. 13e; Briones et al. 1999), que ha sido asignado al Período Inka tanto en el Norte Grande (Briones et al. 1999; Valenzuela et al. 2004) como en la zona central del país (Troncoso 2008).

Sabemos que aunque los resultados alcanzados en este trabajo no son directamente extrapolables hacia los valles de Elqui y Limarí, ellos sí son una buena razón para revaluar las sistematizaciones y las cronologías propuestas para el arte rupestre de tales sectores, y en particular, la supuesta exclusividad del motivo de camélidos en el arte rupestre del Período Alfarero Temprano.

RECONOCIMIENTOS Este trabajo ha sido posible gracias al apoyo de todo el equipo de terreno del Proyecto FondecyT 1080360 que ha permitido relevar este registro y discutir varias de estas ideas. A Donald Jackson, Diego Salazar y evaluadores anónimos por sus comentarios que permitieron subsanar una serie de errores del trabajo. A Isabel Cartajena por discutir algunos aspectos de la representación de los camélidos y por su ayuda con los análisis estadísticos. A Andrea Torres por su ayuda editorial. Obviamente, errores y omisiones siguen siendo mi responsabilidad.

\section{NOTAS}

${ }^{1}$ Debemos recordar en este punto que en nuestros trabajos hemos reconocido un total de 1630 bloques de arte rupestre, lo que hace imposible el registro de todo este universo, por lo que se ha optado por seleccionar concentraciones de soportes para su fichaje. Esta selección ha tomado como criterios la complejidad de estos conjuntos, su emplazamiento, altura, tipos de diseño y técnicas presentes, entre otros.

2 Corresponden a camélidos cuyas extremidades presentan pies partidos y fue utilizado por Ballereau y Niemeyer (1999), para describir algunos ejemplares del Norte Semiárido.

${ }^{3}$ Debido a la alta heterogeneidad de los diseños no figurativos, que son los recurrentes acompañantes de los camélidos en los paneles, no es posible realizar un estudio más específico para evaluar la asociación que se da entre ambos conjuntos de representaciones en busca de algún patrón.

\section{REFERENCIAS}

Ampuero, G. \& M. Rivera, 1971. Las manifestaciones rupestres y arqueológicas del valle del Encanto. Boletín del Museo Arqueológico de La Serena 14: 71-103, La Serena.

Arenas, M. \& J. L. Martínez, 2009. Construyendo nuevas imágenes sobre los otros en el arte rupestre andino colonial. Revista Chilena de Antropología Visual 13: 17-36, Santiago.

Armstrong, F., 2012. Engraved memory: Petroglyphs and collective memory at Los Mellizos, Illapel, Chile. Rock Art Research 29 (1): 19-34.

Aschero, C., 1999. El arte rupestre del desierto puneño y el noroeste argentino. En Arte rupestre en los Andes de Capricornio, J. Berenguer \& F. Gallardo, Eds., pp. 97-134. Santiago: Museo Chileno de Arte Precolombino.

Ballereau, D. \& H. Niemeyer, 1999. Los sitios rupestres del valle del río Hurtado Superior (Norte Chico, Chile). Chungara 31 (2): 229-292.

Becker, C., 2004. Animales que cuentan historias. Chungara, volumen especial, tomo II: 359-364.

Becker, C. \& I. Cartajena, 2005. Las ofrendas de camélidos en el cementerio de la plaza Coquimbo, una nueva mirada. Fondo de Apoyo a la Investigación Patrimonial. Informes, pp. 77-86. Santiago.

Berenguer, J., 1998. Identificación de camélidos en el arte rupestre de Taira: ¿Animales silvestres o domésticos? Chungara 28 (1-2): 85-114.

— 2004a. Cinco milenios de arte rupestre en los Andes atacameños: Imágenes para lo humano, imágenes para lo divino. Boletín del Museo Chileno de Arte Precolombino 9: 75-108.

- 2004b. Caravanas, interacción y cambio en el desierto de Atacama. Santiago: Ediciones Sirawi.

Berenguer, J.; G. Cabello \& D. Artigas, 2007. Tras la pista del Inka en petroglifos paravecinales al Qhapaqñan en el Alto Loa, norte de Chile. Chungara 39 (1): 29-50.

Briones, L.; P. Clarkson, A. Díaz \& C. Mondaca. 1999. Huasquiñas, las chacras y los geoglifos del desierto: una aproximación al arte rupestre andino. Diálogo Andino 18: 39-61, Arica.

Cabello, G., 2001. Acercamiento al arte rupestre Diaguita a partir de las máscaras del valle de Chalinga, IV Región. En Actas del IV Congreso Chileno de Antropología, tomo II, pp. 13631370, Santiago.

2011. De rostros a espacios compositivos: Una propuesta estilística para el valle de Chalinga, Chile. Chungara 43 (1): 25-36.

Castillo, G., 1985. Revisión del arte rupestre Molle. En Estudios en Arte Rupestre, C. Aldunate, J. Berenguer \& V. Castro, Eds., pp. 173-194. Santiago: Museo Chileno de Arte Precolombino.

1986. Sociedades agropecuarias tempranas y control de recursos en el ambiente semiárido de Chile. Chungara 16-17: 173-180.

- 1989. Agricultores y pescadores del Norte Chico: El Complejo Las Animas (800-1200 DC). En Prehistoria: Desde sus orígenes hasta los albores de la conquista, J. Hidalgo, V. Schiappacasse, H. Niemeyer, C. Aldunate \& I. Solimano, Eds., pp. 265-276. Santiago: Editorial Andrés Bello.

- 1991. Desarrollo prehispánico en la hoya hidrográfica del río Choapa. Manuscrito depositado en el Museo Arqueológico de La Serena.

GAllardo, F., 2004. El arte rupestre como ideología: Un ensayo acerca de pinturas y grabados en la localidad del río Salado (norte de Chile). Chungara, volumen especial, tomo II: 427-440.

Gallardo, F.; V. Castro \& P. Miranda, 1990. Jinetes sagrados en el desierto de Atacama: Un estudio de arte rupestre andino. Boletín del Museo Chileno de Arte Precolombino 4: 27-56.

Gallardo, F. \& F. Vilches, 1995. Nota acerca de los estilos de arte rupestre en el pukara de Turi. Boletín de la Sociedad Chilena de Arqueología 23: 31-33, Santiago.

— 2001. Arte rupestre en la época de dominación Inka en el norte de Chile. En Tras la buella del Inka en Chile, pp. 34-43. Santiago: Museo Chileno de Arte Precolombino. 
Gallardo, F. \& H. YacoBaccio, 2005. Wild or domesticated? Camelids in Early Formative Rock Art of the Atacama Desert (Northern Chile). Latin American Antiquity 16 (2): 115-130.

- 2007. ¿Silvestres o domesticados? Camélidos en el arte rupestre del Formativo Temprano en el desierto de Atacama (norte de Chile). Boletín del Museo Chileno de Arte Precolombino 12 (2): 9-31.

García, J., 2005. Estudio espacial de los petroglifos del llano de San Agustín, valle del río Hurtado, IV Región, Chile. Memoria para optar al título de Arqueólogo. Departamento de Antropología, Universidad de Chile, Santiago.

González, J., 2003. Etología de camélidos y arte rupestre de la subregión del río Salado (norte de Chile, II región). Estudios Atacameños 23: 23-32.

González, P., 2004. Patrones decorativos y espacio: El arte visual Diaguita y su distribución en la cuenca del río Illapel. Chungara, volumen especial, tomo II: 767-781.

- 2011. Universo representacional del arte rupestre del sitio Los Mellizos (Provincia del Choapa): Convenciones visuales y relaciones culturales. Boletín del Museo Chileno de Arte Precolombino 16 (2): 49-59.

JaCKSON, D., 2005. Camélidos en el arte rupestre de la cuenca hidrográfica del río Choapa, hacia una discusión de sus distinciones. Trabajo presentado en el V Congreso Nacional de Antropología, San Felipe.

Jackson, D.; D. Artigas \& G. CABello, 2002. Trazos del Choapa: Arte rupestre en la cuenca del río Choapa, una mirada macroespacial. Santiago: LOM.

Klanch, E. \& M. Aldenderfer, 2001. Qawrankasax waljawa: Arte rupestre de cazadores y pastores en el río Ilave (sur del Perú). Boletín del Museo Chileno de Arte Precolombino 8: 47-58.

Martínez, J. L., 2009. Registros andinos al margen de la escritura: el arte rupestre colonial. Boletín del Museo Chileno de Arte Precolombino 14 (1): 9-35.

Méndez, C.; A. Troncoso, D. Jackson \& D. Pavlovic, 2009. Uso del espacio entre cazadores recolectores tardíos en espacios cordilleranos del norte semiárido de Chile. Intersecciones en Antropología 10: 313-326, Olavarría.

Niemeyer, H. \& D. Ballereau, 1998. Los petroglifos del cerro La Silla provincia de Coquimbo. Chungara 28 (1-2): 277-317.

Niemeyer, H. \& G. CASTillo, 1996. Los yacimientos arqueológicos del estero San Pedro de Quiles. Boletín del Museo Arqueológico de La Serena 19: 53-72, La Serena.

Niemeyer, H.; G. Castillo \& M. Cervellino, 1989. Los primeros ceramistas del Norte Chico: Complejo El Molle (0 a 800 DC) En Culturas de Chile. Prebistoria, J. Hidalgo, V. Schiappacasse, H. Niemeyer, C. Aldunate \& I. Solimano, Eds., pp. 227-263. Santiago: Editorial Andrés Bello.

NúÑEz, L. \& T. DILlEHAY, 1995 [1979]. Movilidad giratoria, armonía social y desarrollo en los Andes Meridionales: Patrones de tráfico e interacción económica. Antofagasta: Universidad Católica del Norte.
Pavlovic, D., 2004 Dejando atrás la tierra de nadie: asentamientos, contextos y movilidad de las comunidades alfareras tempranas del Choapa. Werken 5: 39-46.

SepúlvedA, M., 2004. Esquemas visuales y emplazamiento de las representaciones rupestres de camélidos del Loa Superior en tiempos inkaicos, ¿una nueva estrategia de incorporación de este territorio al Tawantinsuyu? Chungara 36 (2): 439-452.

— 2008. Arte rupestre en tiempos inkaicos: Nuevos elementos para una nueva discusión. En Lenguajes visuales del Inka, P. González \& T. Bray, Eds., pp. 111-124. Oxfordshire: British Archaeological Reports S1848.

Troncoso, A., 1999. La Cultura Diaguita en el valle de Illapel: Una perspectiva exploratoria. Chungara 30 (2): 125-142.

- 2004. Relaciones socioculturales de producción, formas de pensamiento y ser en el mundo: Un acercamiento a los períodos Intermedio Tardío y Tardío en la cuenca del río Choapa. Werken 5: 61-68.

— 2008. Arte rupestre en la cuenca del río Aconcagua: formas, sintaxis, estilo y poder. Traballos de Arqueoloxía e Patrimonio (TAPA) 39, Santiago de Compostela.

- 2009. Formas, estilo y espacio en el arte rupestre del Valle El Encanto, IV región, Chile. Informe Final Proyecto SOC 07/17-2, Vicerrectoría de Investigación y Desarrollo. Santiago: Universidad de Chile.

- 2010. Formas, estilo y espacio en el arte rupestre de Illapel y Chalinga, Provincia del Choapa. Informe Final Proyecto FONDECYT 1080360.

- 2011. Personajes fuera de lugar: Antropomorfos tardíos en el arte rupestre del Norte Semiárido de Chile. Intersecciones en Antropología 12 (1): 221-230. Olavarría.

Troncoso, A. \& D. Pavlovic, 2010. Historia, saberes y prácticas: Un ensayo sobre el desarrollo de las comunidades alfareras del Norte Semiárido. Revista Chilena de Antropología [en prensa].

Troncoso, A.; D. Pavlovic, C. Becker, P. González \& J. Rodríguez, 2004. Césped 3, asentamiento del período Diaguita-Inkaico sin cerámica Diaguita Fase III en el curso superior del río Illapel, IV Región, Chile. Chungara, volumen especial, tomo II: 893-906.

Troncoso, A.; F. Armstrong, F. Vergara, P. Urzúa \& P. Larach, 2008. Arte rupestre en el valle El Encanto: Hacia una revaluación del sitio-tipo del Estilo Limarí. Boletín del Museo Chileno de Arte Precolombino 13 (2): 9-36.

Troncoso, A.; C. Becker, D. Pavlovic, P. González, J. Rodríguez \& C. Solervicens, 2009. El sitio LV099-B Fundo Agua Amarilla y la ocupación del período inkaico en la costa de la Provincia del Choapa-IV Región. Chungara 41 (2): 241-259.

Valenzuela, D.; C. Santoro \& A. Romero, 2004. Arte rupestre en asentamientos del período Tardío en los valles de Lluta y Azapa, Norte de Chile. Chungara 36 (2): 421-438.

Vilches, F. \& M. URIBE, 1999. Grabados y pinturas del arte rupestre tardío de Caspana. Estudios Atacameños 18: 73-88. 
